\title{
A NOVEL ROLE FOR ARGININE IN ENHANCING NEONATAL
}

\section{THERMOGENESIS}

\author{
A Thesis \\ by \\ SORIN MEREDITH GREFF \\ Submitted to the Office of Graduate Studies of \\ Texas A\&M University \\ in partial fulfillment of the requirements for the degree of \\ MASTER OF SCIENCE
}

August 2011

Major Subject: Physiology of Reproduction 
A Novel Role for Arginine in Enhancing Neonatal Thermogenesis Copyright 2011 Sorin Meredith Greff 


\title{
A NOVEL ROLE FOR ARGININE IN ENHANCING NEONATAL THERMOGENESIS
}

\author{
A Thesis \\ by \\ SORIN MEREDITH GREFF
}

\begin{abstract}
Submitted to the Office of Graduate Studies of
Texas A\&M University

in partial fulfillment of the requirements for the degree of

MASTER OF SCIENCE
\end{abstract}

\begin{abstract}
Approved by:
Chair of Committee, Michael C. Satterfield

Committee Members, Thomas H. Welsh Jr.

Guoyao $\mathrm{Wu}$

Thomas E. Spencer

Head of Department, H. Russell Cross
\end{abstract}

August 2011

Major Subject: Physiology of Reproduction 


\begin{abstract}
A Novel Role for Arginine in Enhancing Neonatal Thermogenesis. (August 2011)

Sorin Meredith Greff, B.S, Texas A\&M University

Chair of Advisory Committee: Dr. Michael C. Satterfield
\end{abstract}

Maintenance of body temperature is one of the first and most important physiological processes that must be initiated after birth. Failure to sustain homeothermy leads to hypothermia and death. Indeed, in sheep, $40 \%$ of non-predator lamb deaths are attributed to cold and cold-related causes. Brown adipose tissue (BAT) is an essential mediator of thermogenesis in many species and is responsible for $50 \%$ of the heat generated in the newborn lamb despite comprising only $2 \%$ of body weight. Previously, we found that maternal arginine supplementation increased fetal peri-renal BAT by $62 \%$. This observation led us to test the hypothesis that increased the amount of fetal BAT will enhance neonatal thermogenesis at birth and thus combat the effects of cold stress. Thirty-one multiparous Suffolk ewes gestating singletons and twins were assigned to receive either intravenous injections of L-arginine (27 mg/kg bodyweight; $\mathrm{n}=17)$ or sterile saline $(\mathrm{n}=14)$ three times daily from Day 75 to Day 125 of gestation (term=147). Following parturition lambs were removed from their dams, placed in a thermoneutral environment, and fed artificial colostrum on a per body weight basis. At 4 hours of age, lambs were cold challenged at $0^{\circ} \mathrm{C}$ for 2 hours. Rectal temperatures were recorded at 15 minute intervals. At 6 hours of age all singletons and one lamb of each 
twin pair was sacrificed. The remaining twin lamb was challenged again at 22 hours of age for an additional 2 hours prior to necropsy. Rectal temperature was greater for the duration of both cold challenges in lambs from arginine-treated ewes than lambs from saline-treated ewes $(\mathrm{P}<0.050)$. Interestingly, at time of necropsy, BAT weight did not differ $(\mathrm{P}>0.10)$ between treatments. UCP1 mRNA levels were not affected by treatment or age (P>0.10). However, TEK, PPARGC1A, NRF1, NRF2, PPARG, ADRB3, ARG2, RPS6KA1, EIF4EBP1, ODCl were not affected by treatment $(\mathrm{P}>0.10)$ but were upregulated $(\mathrm{P}<0.05)$ by age; being greater at 24 hours of age versus 6 hours of age. Results indicate that maternal arginine treatment results in increased neonatal thermogenesis after birth. Although the underlying mechanisms remain to be elucidated, the data reported herein represent the first step in improving neonatal survival in response to cold. 


\section{ACKNOWLEDGEMENTS}

First I would like to thank my parents for their guidance and support throughout my life. They have always gone above and beyond to help me better my education and life experiences and without them I would not have made it this far in my career. I am truly thankful for everything they have done.

I would also like to thank my advisor, Dr. Carey Satterfield for believing in me and my goals and taking me on as his first graduate student. I am extremely grateful for the knowledge that he has taught me, whether it be in the classroom, lab, or in the field. What I have learned here over the past two years under Dr. Satterfield can never be replaced and I am truly thankful for his support and guidance throughout my graduate career. Thank you also to my other committee members, Dr. Spencer, Dr. Welsh, and $\mathrm{Dr}$. Wu for their guidance throughout the course of this research. Special thanks also to the members of PREP section as well as the Department of Animal Science for helping to fund my education here at Texas A\&M. This project was funded by the National Research Initiative Competitive Grant 2009-35206-05211 from the USDA National Institute of Food and Agriculture and would not have been possible without their support.

Finally I would like to thank Becky Simmons for her invaluable help throughout my research. Becky was always more than helpful in the lab and I would never have finished on time without her help. She was always willing to help no matter what else was going on and I am grateful I was able to work with her and get to know her. Also, I 
would like to thank Jason McKnight for helping with the laborious stages of my research and helping me with life in general! He was always willing to help whether it was feeding sheep, administering injections, or helping lamb, no matter what time of the night it was. I am truly thankful to have had his help and am so lucky to have him in my life! 


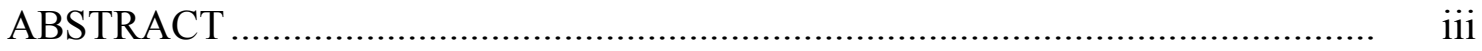

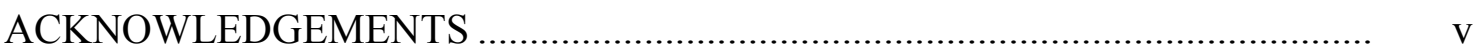

TABLE OF CONTENTS ….......................................................................... vii

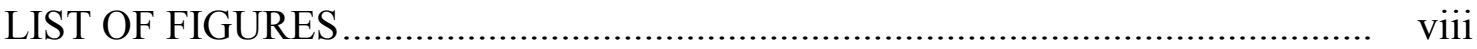

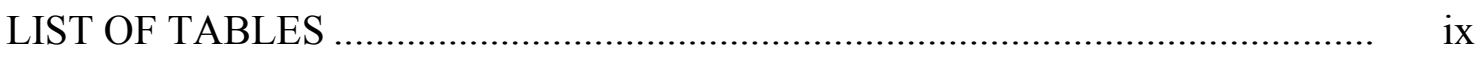

CHAPTER

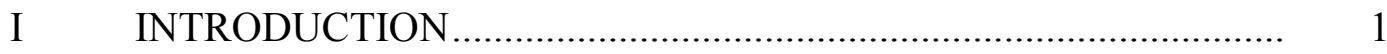

II LITERATURE REVIEW ......................................................

Histology and microscopy of BAT .............................................. 3

Lineage of brown adipocyte formation in the rat ............................. 6

BAT activation and thermogenesis ............................................... 9

UCP1: The protein of BAT …………………………….......... 13

UCP1: Importance in BAT and thermogenesis............................. 15

Nutritional regulation of BAT and thermogenic capacity............. 16

BAT and arginine: Signaling possibilities ...................................... 23

Summary and objectives ......................................................... 30

Hypothesis ……………………………………………........... 31

III A NOVEL ROLE FOR ARGININE IN ENHANCING NEONATAL THERMOGENESIS...................................................................... 32

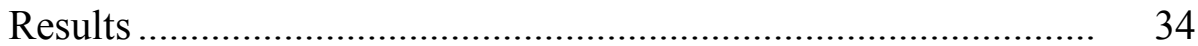

Discussion ....................................................................... 43

Materials and methods ................................................................ 49

IV SUMMARY AND DIRECTION OF FUTURE RESEARCH ............ 58

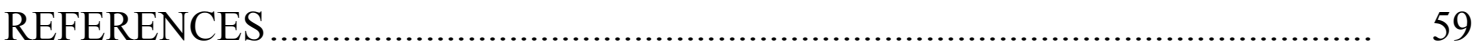

VITA 


\section{LIST OF FIGURES}

FIGURE Page

2.1 Microscopic Comparison of Brown and White Adipocytes ..................... 5

2.2 Proposed Model for Brown and White Adipocyte Development ............. 9

2.3 Depiction of the Non-Shivering Thermogenesis Process ....................... 13

2.4 UCP1 Mechanism for Heat Generation.................................................. 15

2.5 Effects of Maternal Nutrition on Fetal BAT Weight ............................ 21

2.6 Proposed Mechanism of Arginine Involvement in BAT Growth and Development ............................................................................. 24

2.7 Possible Roles of Nitric Oxide in Mitochondrial Biogenesis .................. 27

2.8 Proposed Role of Polyamines and Arginine Supplementation as Regulated by Maternal Nutrition .............................................................. $\quad 30$

3.1 Neonatal Lamb Body Temperature during a 2-Hour Cold Challenge at $0^{\circ} \mathrm{C}$.

3.2 Gross Morphology of BAT from Lambs Born to Saline and Arginine Treated Mothers

3.3 Immunohistochemical Localization of VWF in Sections of BAT ............. 41

3.4 Immunohistochemical Localization of Ki67 in Sections of BAT ............. 41

3.5 Immunohistochemical Localization of UCP1 in Sections of BAT ........... 42

3.6 Immunohistochemical Localization of VDAC in Sections of BAT.......... 42

3.7 Experimental Design .............................................................. $\quad 50$ 


\section{LIST OF TABLES}

TABLE Page

2.1 Histological Differences Between BAT and WAT ............................... 5

2.2 Summary of Nutritional Manipulations to Enhance BAT and/or Thermogenic Capacity .................................................................... 22

3.1 Lamb Plasma Concentrations of Free Fatty Acids, Glucose, and Norepinephrine at 0, 4, 6, 22, 24 Hours of Age....

3.2 Effect of Arginine Treatment, Age, and Their Interaction on BAT Weight and Cellular Content.

3.3. BAT Oxidation of Leucine, Oleic Acid, Glucose, and Glutamine 40

3.4 Effect of Age at Challenge Time and Treatment on BAT gene mRNA Expression by Real-Time PCR Presented as Fold Difference

3.5 Primer Sequences for Real-Time Quantitative PCR 


\section{CHAPTER I}

\section{INTRODUCTION}

Brown adipose tissue (BAT) research over the years has greatly expanded the knowledge of the unique characteristics and physiological functions of this tissue. The recent finding that BAT is present in adult humans and is metabolically active has further stimulated research of BAT (Virtanen et al. 2009). Notably, it is hypothesized that BAT can help control obesity and the effects of obesity such as diabetes, hypertension, and heart disease (Frühbeck et al. 2009). It has also been extensively studied in the field of neonatal survival and thermogenesis due to cold exposure. Research in sheep has shown that cold weather-related losses, including starvation due to hypothermia, make up approximately $40 \%$ of the total non-predator lamb deaths (Simpson 1995). Neonatal survival directly depends on the ability of the newborn to maintain core body temperature. Following parturition, the fetus is introduced into an environment that is much cooler than the uterine environment and must immediately begin to adapt to this temperature change. An important way the newborn regulates its core body temperature and adapts to the temperature change is through non-shivering thermogenesis. Non-shivering thermogenesis directly depends on BAT because of its ability to rapidly generate heat. At birth, the metabolism of BAT for non-shivering thermogenesis accounts for approximately $50 \%$ of the heat generated (Symonds and Lomax 1992).

This thesis follows the style of Molecular Reproduction and Development. 
This is a remarkable characteristic given that BAT only accounts for about $2 \%$ of the animal's weight at birth (Symonds and Lomax 1992). Unfortunately, the ability of BAT to quickly generate heat deteriorates rapidly during the first weeks following parturition (Symonds and Lomax 1992). After 3 weeks of age, BAT begins to adopt WAT characteristics and is indistinguishable from white adipose tissue (WAT) by 1 month of age (Casteilla et al. 1989). Neonatal mortality is a major concern for sheep producers, as most preweaning lamb deaths occur within the first few weeks of life (Alexander 1984; Nowak et al. 2000; Watson 1972). The activation of non-shivering thermogenesis immediately after birth is critical to preventing hypothermia in newborns (Clarke and Symonds 1998). Due to the nature of BAT, finding ways to enhance its effects on the newborn lamb would be an important step to increasing lamb survivability. 


\section{CHAPTER II}

\section{LITERATURE REVIEW}

\section{HISTOLOGY AND MICROSCOPY OF BAT}

Histologically, WAT and BAT have many significant differences regarding number of lipid droplets, mitochondrial number and size, and most importantly, function. White adipocytes are comprised of a single large lipid droplet and have a small amount of mitochondria in comparison to brown adipocytes which contain numerous small lipid droplets that are surrounded by a large number of mitochondria (Richard and Picard 2011). This increased amount of mitochondria is responsible for the brown coloration that BAT is known for because of the iron-containing pigments that are present within the mitochondria (Timmons et al. 2007). The mitochondria within brown adipocytes are also more developed than the mitochondria in white adipocytes, being larger $(>0.5 \mu \mathrm{m}$ versus $<0.3 \mu \mathrm{m}$ in WAT) (Afzelius 1970). In BAT many mitochondria are required for the oxidation of fatty acids released from triglycerides. The difference in size is due to the larger surface are of the inner mitochondrial membrane, which contains the unique protein, uncoupling protein-1 (UCP1), making up $15 \%$ of the protein in the inner mitochondrial membrane (Lindgren and Barnard 1972; Voet et al. 2008). The ability of BAT to generate large amount of heat is due to the presence of UCP1. The presence of UCP1 has been correlated to the amount of heat produced by the tissue (Nicholls et al. 1986). Brown adipose tissue is also more highly vascularized than WAT, which usually contains one capillary to provide nutrient supply to the cell. This 
vascularization in BAT is important for the increased blood flow required to obtain nutrients needed for enhanced thermogenesis. These blood vessels are lined with endothelial cells which represent the major cell type within BAT (Cannon and Nedergaard 2004). The vasculature is also important because it forms a system to convey the capture and redistribution of heat. Extensive vascularization also contributes to the brown color of the tissue. Activation of BAT is under adrenergic control and thus innervated by postganglionic nerve fibers of the sympathetic nervous system, which is responsible for the release of norepinephrine (Morrison 2004). The most common adrenergic receptor in BAT is the $\beta 3$ receptor and it is considered the most important receptor to indicate the presence of mature functional BAT, as it is absent in brown adipocyte precursor cells (Cannon and Nedergaard 2004). The $\beta 3$ receptor has also been shown to be required for lipolysis, as $\beta 3$ knockout mice have fully functional BAT but develop obesity (Konkar et al. 2000). The differences between WAT and BAT can be summarized in Table 2.1 and Figure 2.1. 
TABLE 2.1. Histological differences between WAT and BAT.

\begin{tabular}{|c|c|c|}
\hline & Brown Adipose Tissue (BAT) & White Adipose Tissue (WAT) \\
\hline Function & Heat Production & Energy storage, heat insulation \\
\hline Lipid Droplet Size & Multilocular & Unilocular \\
\hline Mitochondria & Many, well developed, larger & Few, not well developed \\
\hline UCP1 & Abundant & None \\
\hline $\begin{array}{c}\text { Vascularization } \\
\text { C3 Adrenergic } \\
\text { Receptor }\end{array}$ & High & White \\
\hline Brown & Present & Absent \\
\hline
\end{tabular}

BAT and WAT differ in function, morphology, color, protein content, and level of vascularization.

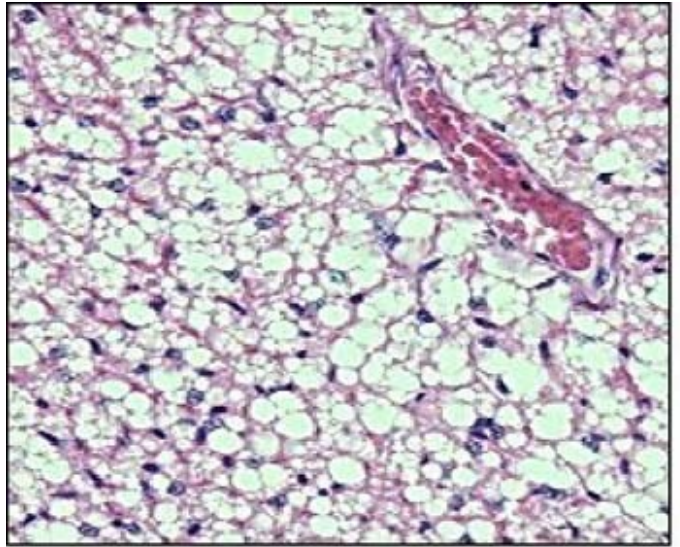

Brown adipocytes

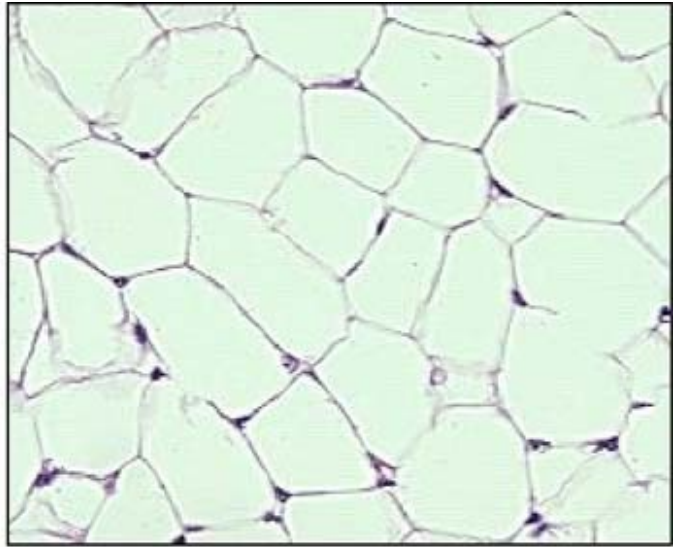

White adipocytes

Figure 2.1. Microscopic comparison of brown and white adipocytes. 


\section{LINEAGE OF BROWN ADIPOCYTE FORMATION IN THE RAT}

Brown adipose tissue development is one of the most important processes that occurs during fetal development of a number of mammalian fetuses including rats, lambs, and humans. In order to obtain a more complete understanding of fetal BAT development, an understanding of the BAT cell lineage is needed. In the rat, adipocytes for BAT and WAT originate from the same mesoderm layer, where myocytes, chondrocytes, osteoblasts and connective tissue also originate (Enerbäck 2009). Adipogenesis begins with undifferentiated cells from the mesoderm layer, known as mesenchymal stem cells. With the presence of peroxisome proliferator activated receptor gamma (PPARG), these cells give rise to adipoblasts that eventually develop into preadipocytes. Differentiation of brown adipocytes and white adipocytes requires $P P A R G$ as it is one of the master regulators of BAT development, with a knockdown of PPARG resulting in an absence of discernable adipose tissue (Barak et al. 1999; Koppen and Kalkhoven 2010). The preadipocytes will ultimately differentiate into mature adipocytes that are capable of lipid storage and function in lipolysis and lipogenesis. White preadipocytes also express a factor that is absent in brown preadipocytes, CD24 (Koppen and Kalkhoven 2010). Although BAT development is initially dependent on PPARG to differentiate the stem cell into a preadipocyte, more is needed to differentiate the preadipocytes into brown adipocytes. A recent study in mice has shown that brown and white adipocytes may develop from different origins (Seale et al. 2008). Myocytes and brown adipocytes are believed to have similar stem cell origins because both express the myogenic factor 5, MYF5, while white adipocytes do not. Further differentiation is 
then determined by the absence or presence of the transcription factor, PR domain containing 16 (PRDM16), another master regulator of brown adipose tissue (Virtanen et al. 2009). PRDM16 controls the fate of these cells, as expression of the factor induces brown adipocyte formation and lack of the factor induces a loss of brown adipose tissue characteristics and myocyte formation (Enerbäck 2009; Seale et al. 2008). Once the brown adipocytes have reached maturity they are able to carry out their purpose of nonshivering thermogenesis.

Additionally, the presence of another important factor, $P P A R G$ coactivator-1 $\alpha$ $(P P A R G C 1 A)$ allows for a transcriptional switch that stimulates mitochondrial genes in BAT in response to cold (Puigserver et al. 1998). During BAT development, $P P A R G C 1 A$ expression begins early in brown adipocyte differentiation, with the highest levels found in mature brown adipocytes and also induces the expression of UCP1 (Uldry et al. 2006). In response to cold, PPARGC1A upregulates several important processes required for thermogenesis within BAT such as fuel intake, fatty-acid oxidation, mitochondrial biogenesis, and increased oxygen consumption through coactivation of other genes, including PPARs and nuclear respiratory factor $1(N R F 1)$ (Wu et al. 1999). Notably, mice deficient in PPARGC1A are cold sensitive, have decreased expression of $U C P 1$, and also have morphological abnormalities of the BAT such as an abundance of large lipid droplets (Lin et al. 2004). However, it is interesting to note that while PPARGC1A is required for adequate BAT function, it is not required for differentiation of brown preadipocytes (Uldry et al. 2006). 
Interestingly, it has also been shown that brown adipocytes are present in WAT that has been repeatedly exposed to cold or $\beta$-adrenergic stimulation (Guerra et al. 1998). These cells do not originate from the same MYF5 positive cells, as indicated by the lack of MYF5 expression but have the ability to express $U C P 1$ and respond to $\beta$-adrenergic stimulation (Guerra et al. 1998; Seale et al. 2008). The brown adipocyte like cells are often termed "brown-like adipocytes" or "beige" adipocytes.

Thus, it is clear that several factors such as PPARG, PRDM16, MYF5, and PPARGC1A (Figure 2.2) are required for proper BAT development and function. Successful development of brown adipocytes is essential for extrauterine environment adaptation, with BAT being required for heat production. While the brown adipocyte lineage is better understood in the rat, it has not been thoroughly studied in sheep. Using what is known about the cell lineage in rats has been the basis of numerous studies in other species. 


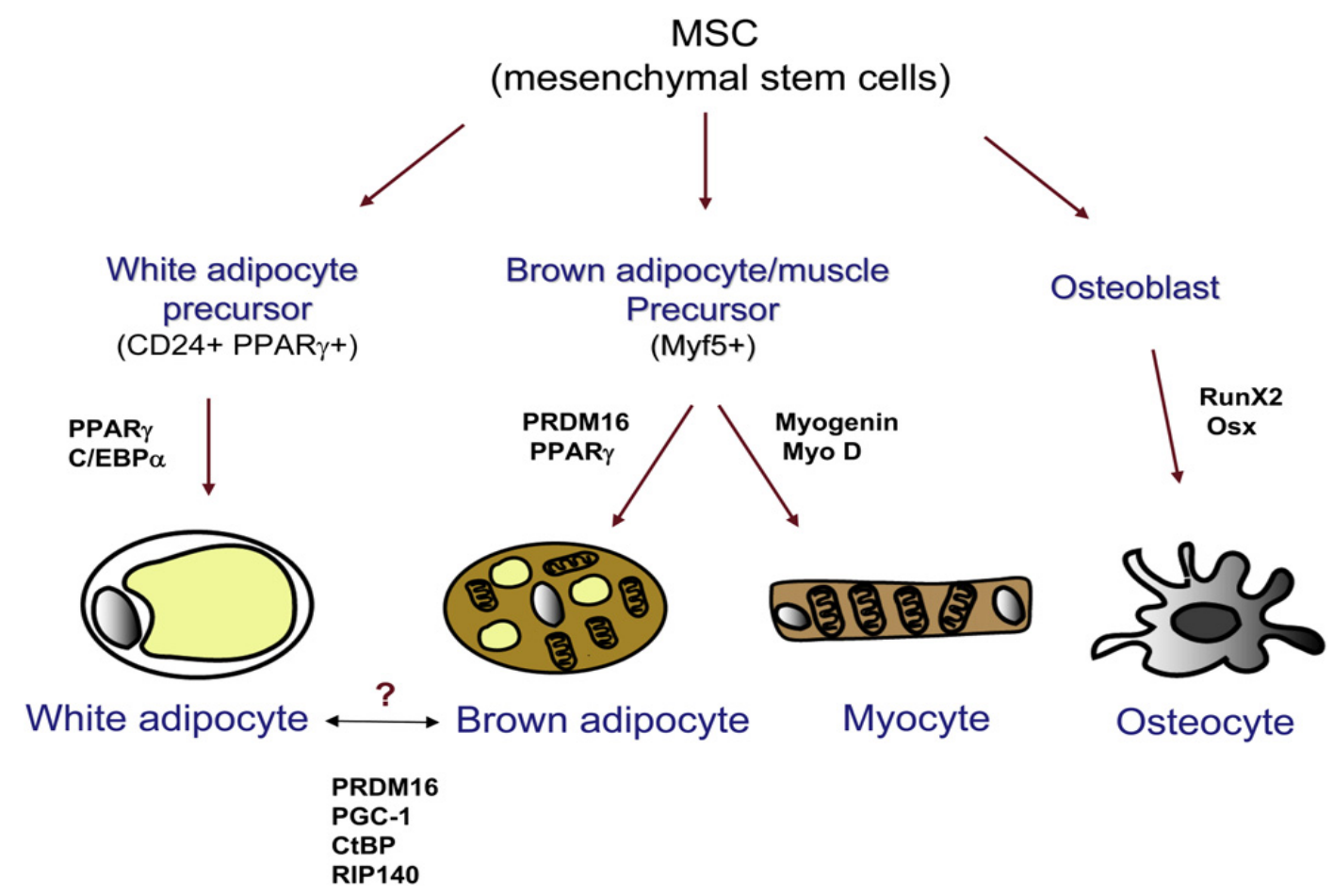

Figure 2.2. Proposed model for brown and white adipocyte development. White and brown adipocytes are derived from the same mesodermal layer, with white preadipocytes expressing $C D 24$ and $P P A R G$ and brown preadipocytes expressing MYF5. Brown adipocytes also express PPARG, but $M Y F 5$ acts as the differentiating factor between to two types of fat cells. MYF5 positive progenitor cells give rise to mature brown adipocytes and myocytes with PRDM16 directing brown adipocyte formation (Won Park et al. 2008).

\section{BAT ACTIVATION AND THERMOGENESIS}

In mammals, the two methods used to maintain core body temperature are shivering and non-shivering thermogenesis. These two processes have different mechanisms, with shivering thermogenesis relying on muscle fiber cross-bridging involving hydrolysis of ATP into ADP and $\mathrm{P}_{\mathrm{i}}$ to generate heat through muscle movement (Cannon and Nedergaard 2004). Non-shivering thermogenesis relies on $U C P 1$ to provide a proton leak channel in the inner mitochondrial membrane that 
uncouples the electron transport process and bypasses ATP synthesis, which allows for heat production without using a substantial amount of energy (Voet et al. 2008). Because of this process, BAT is capable of producing 150-300 times more heat per kilogram of tissue than organs lacking BAT (Power 1989).

Interestingly, of the mammalian species studied, BAT has been identified in all species except swine (Cannon and Nedergaard 2004). Piglets rely solely on shivering thermogenesis as their main mechanism in combating cold temperatures and it is hypothesized that the gene normally found in BAT, UCP1, was mutated millions of years ago in the pig lineage (Berg et al. 2006). All other mammals rely directly on BAT and non-shivering thermogenesis to maintain a core body temperature in response to cold. In the lamb, the major site of BAT is located in the peri-renal region $(80 \%)$, with other depots forming around the heart and interscapular region (Alexander 1981). This is different than BAT formation in rodents and other hibernating animals, whose major storage site is the interscapular region (Alexander 1981). During ovine gestation, fetal BAT formation can be divided into three stages (Symonds and Lomax 1992). During the first stage (Day 70 to 120 of gestation), hypertrophy and hyperplasia cause rapid tissue growth. The second and third stages (Day 120 to term), involve increased cell differentiation and maturation, characterized by the expression of $U C P 1$, also known as thermogenin (Alexander 1978; Symonds and Lomax 1992). Many brown pre-adipocytes can be found in the peri-renal areas around Day 70 of gestation and by Day 90 there is a rapid increase in proliferation of the adipocytes containing numerous mitochondria and increasing lipid (Alexander 1978). Rapid growth of the peri-renal BAT occurs until Day 
120 , increasing the amount per kilogram of the body weight. After Day 120, growth begins to slow and occurs at a proportional rate with the fetus (Alexander 1978).

As mentioned above, BAT and its vasculature are under adrenergic control of the sympathetic nervous system with the main hormone being norepinephrine. Norepinephrine, released when the body is in a state of stress (i.e. the act of birth or cold stress), is the key regulator of non-shivering thermogenesis in newborns and is also involved in cell proliferation, advanced cell differentiation, and apoptosis inhibition (Cannon and Nedergaard 2004). Once the fetus is removed from the temperaturecontrolled environment of the uterus following parturition, it is immediately faced with the challenge of core temperature regulation which stimulates a cascade of events to generate heat. The process begins by norepinephrine binding to $\beta 3$ adrenergic receptors in the cell membrane of the tissue and activating cyclic adenosine monophosphate (cAMP) which stimulates protein kinase A. Protein kinase A then activates the enzyme, hormone-sensitive triacylglycerol lipase (HSL) through phosphorylation. This enzyme hydrolyzes triacylglycerols to produce free fatty acids. This part of the cascade is known as lipolysis, a crucial element of non-shivering thermogenesis. Free fatty acids are essential to this process because they counteract the inhibitory effects of the purine nucleotides (adenosine diphosphate, adenosine triphosphate, guanosine diphosphate, and guanosine triphosphate) (Cannon and Nedergaard 2004). 
The purine nucleotides inhibit the flow of protons through UCPI and disrupt the reaction. Protons must be allowed to flow through $U C P 1$ in order to break up the proton gradient across the inner mitochondrial membrane (Voet et al. 2008). Free fatty acids are recruited into the mitochondria where $\beta$-oxidation occurs, releasing acetyl coenzyme A for oxidation in the citric acid cycle (Cannon et al., 2004). This series of catabolic events leads to heat generation for the newborn without ATP synthesis and can be summarized in Figure 2.3. Due to this cascade of physiological events, it can be noted that stimulation of lipolysis will induce non-shivering thermogenesis, just as nonshivering thermogenesis will induce lipolysis. Both processes are stimulated by norepinephrine binding to $\beta 3$-adrenergic receptors. Norepinephrine is involved in cell proliferation and differentiation, apoptosis inhibition and also directly regulates the expression of UCP1 (Cannon and Nedergaard 2004). Another important function of norepinephrine is that it has been shown to increase vascular endothelial cell growth in adipose tissue (Bukowiecki et al. 1982). This is significant because endothelial cells, which line the interior surface of blood vessels, make up a large part of brown adipose tissue. 


\section{Non-Shivering Thermogenesis}

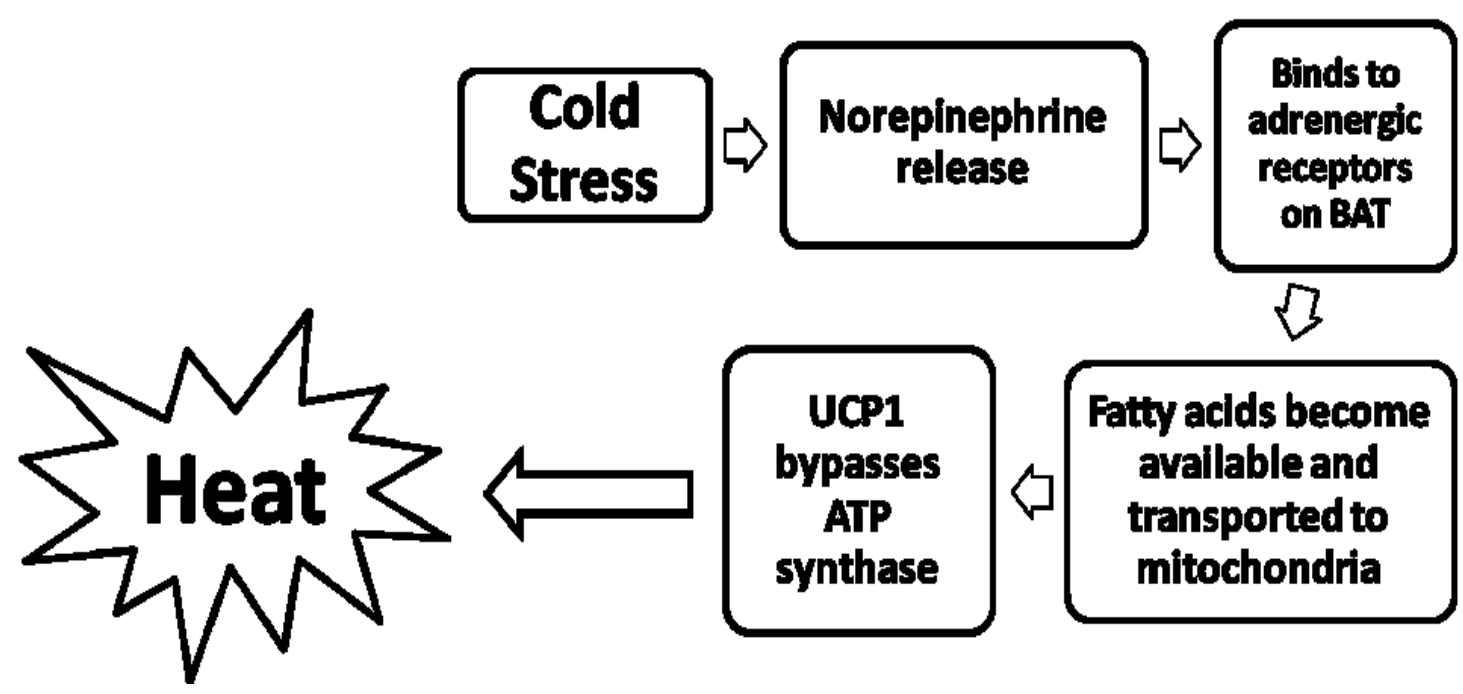

Figure 2.3. Depiction of the non-shivering thermogenesis process. Non-shivering thermogenesis is initiated by cold stress which stimulates norepinephrine release from the sympathetic nervous system to bind to adrenergic receptors within the BAT. Through a series of physiological events, fatty acids are made available and are transported to the mitochondria where they allow protons to flow freely through $U C P 1$, bypassing ATP synthesis and generating heat.

\section{UCP1: THE PROTEIN OF BAT}

UCP1 plays the most important role in non-shivering thermogenesis as it provides for heat generation without using ATP. It was discovered in the nineteen seventies and was known as thermogenin until the discovery of the other UCPs (Mozo et al. 2005; Nicholls and Lindberg 1973). It is part of a UCP superfamily containing four other uncoupling proteins $(U C P 2-5) . \mathrm{UCP} 1$ is a 6-domain transmembrane protein, has a molecular weight of $32-33 \mathrm{kDa}$, varying between species, and is coded by a single 
nuclear gene. The location of the gene is unknown in sheep, and located on chromosome 8 of the mouse and chromosome 4 in the human (Mozo et al. 2005). Recently, the members of this UCP superfamily have been questioned as UCP4 and UCP5 do not share the same ancestor gene that UCP1-3 share, which are believed to have developed through a series of gene duplications (Rial and Zardoya 2009). Furthermore, eutharian or placental mammal UCP1 is the only member of the family that has a thermogenic function, which is carried out by a proton conductance system that is inhibited by purine nucleotides and activated by fatty acids (Richard and Picard 2011). The roles of UCP2 and UCP3, as well as UCP1 from non-eutharian mammals have not been determined, as they do not have this proton conductance system, indicating the unique nature and importance of eutharian UCP1 in thermogenesis (Affourtit et al. 2007).

The exact mechanism of the UCP1 mediated uncoupling process and the involvement of the fatty acids in the uncoupling process has undergone much debate. In order to generate heat, it is currently believed that UCP1 acts as a proton translocator whose activity is inhibited during non-thermogenic conditions by purine nucleotides and is only activated upon adrenergic stimulation of norepinephrine from the sympathetic nervous system (Richard and Picard 2011). The fatty acids are hypothesized to act as proton catalysts that bind protons and transport them to UCP1 where they are translocated across the inner mitochondrial membrane into the mitochondrial matrix (Gonzalez-Barroso et al. 2000; Klingenberg and Echtay 2001). This mechanism can be summarized in Figure 2.4. 


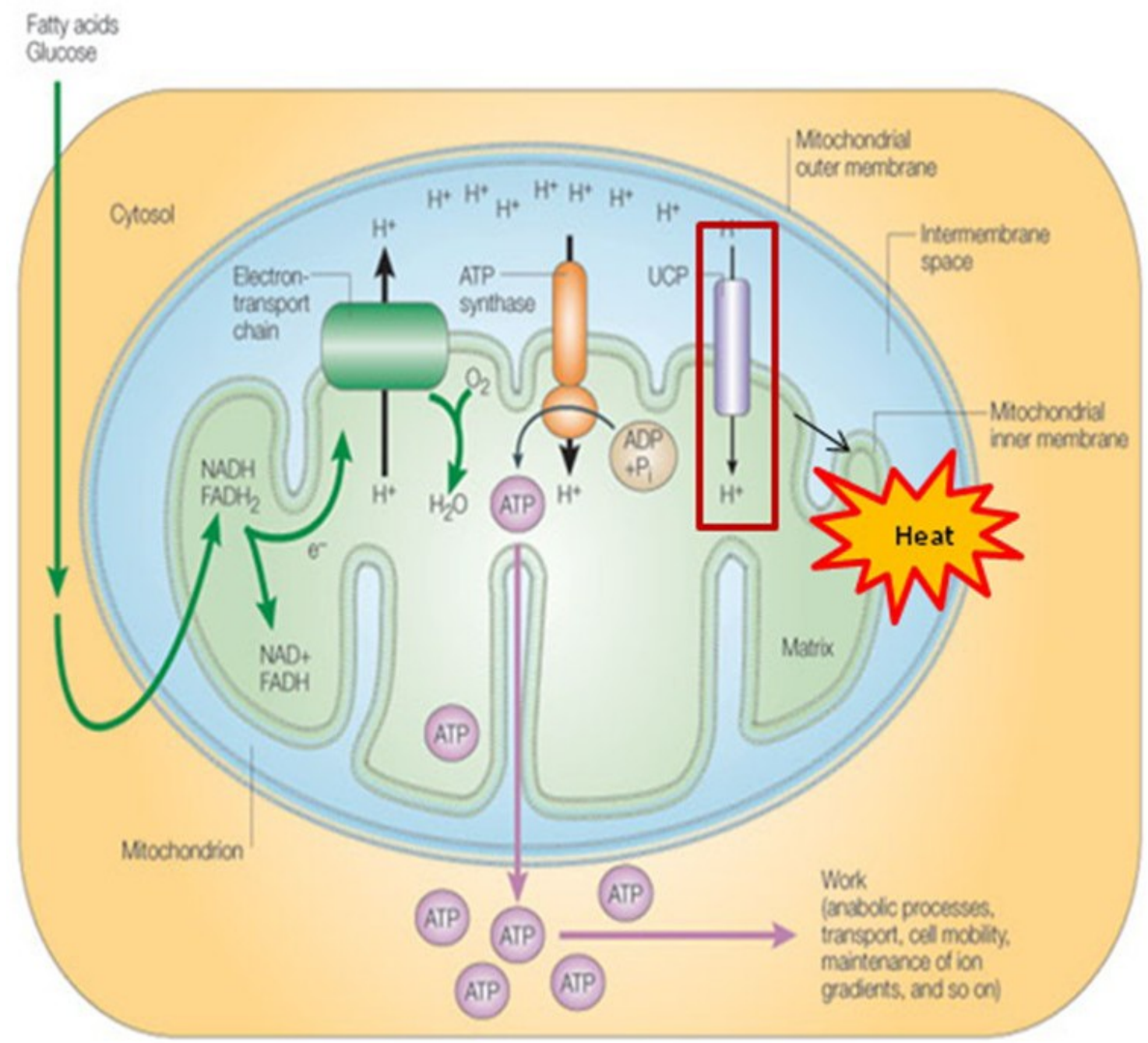

Figure 2.4. UCP1 mechanism for heat generation. UCP1 allows for dissipation of the proton gradient to yield heat with low ATP production. UCP1 allows protons to freely flow through the mitochondrial inner membrane into the matrix of the mitochondria. This UCP1 mediated heat generation uncouples the respiratory chain which allows for fast substrate oxidation with a low rate of ATP production. Adapted from Krauss et al. 2005.

\section{UCP1: IMPORTANCE IN BAT AND THERMOGENESIS}

The importance of this protein in BAT and thermogenesis can be further explained by studies involving UCP1 knockout mice. UCP1 knockout mice become more cold-sensitive and must use other mechanisms to generate heat, such as shivering 
thermogenesis, which requires more energy usage than non-shivering thermogenesis (Kozak and Anunciado-Koza 2008). In addition, UCP1 knockout mice of inbred backgrounds, compared to mice of hybrid background, are extremely sensitive to low temperatures. The mice of inbred background cannot tolerate temperatures of $4^{\circ} \mathrm{C}$ unless they are able to slowly adapt to the change in temperature (Ukropec et al. 2006). Furthermore, in mice lacking $\beta$-adrenergic receptors, induction of PPARGC1A and UCP1 mRNA expression through cold exposure showed a further increase in $P P A R G C 1 A$ and an inhibition of UCP1 indicating that UCP1 $\mathrm{m}$ RNA expression is under adrenergic control (Lehr et al. 2006). Also, recent studies show that PPARGC1A, in addition to UCP1, is required for cold induced thermogenic responses (Uldry et al. 2006). Studies such as these further demonstrate the important thermogenic role of $\mathrm{UCP} 1$ in BAT and the current consensus is that $\mathrm{UCP} 1$ is the only uncoupling protein that is involved in mammalian thermogenesis (Matthias et al. 2000; Nedergaard et al. 1999).

\section{NUTRITIONAL REGULATION OF BAT AND THERMOGENIC CAPACITY}

Cold tolerance has long been a problem for newborn mammals, especially lambs, with approximately $40 \%$ of total non-predator lamb deaths occurring from cold stress (Simpson 1995). Neonatal fatality due to cold stress also greatly impacts the cattle industry with an estimated 95,000 calves dying annually during the neonatal period. This loss results in a \$38 million reduction in income for cow/calf operations (Azzam et al. 1993; Dietz et al. 2003). Since the discovery of BAT and its unique role to maintain body temperature for newborn mammals, the subject of several research studies has focused on increasing the effects of the tissue to enhance thermogenic capacity. Many 
of these studies have focused on nutritional manipulation in order to alter thermogenic capacity and resistance to cold stress.

Brown adipose tissue function is very different in rodents as compared to ruminants. For example, when a calf or lamb is born they rely on BAT and nonshivering thermogenesis to maintain a core body temperature and $U C P 1$ is expressed at maximal levels at the time of birth. In ruminants, BAT is rapidly being used following birth and quickly disappears, typically being absent in the adult. Rodents however typically huddle together in a nest after birth and UCP1 does not reach maximal levels until approximately two weeks after birth and are able to maintain functional BAT throughout their lifetime (Cannon et al. 1988). Because of this unique characteristic, rodents are an excellent model for studying nutritional regulation of BAT and its effects. It is important to note that not only is the abundance of $U C P 1$ important, but also the amount of fat is central in efficient thermogenesis (Symonds and Lomax 1992). A study that elucidated the role of blood flow to BAT during thermogenesis showed that blood flow to scapular (major BAT depot in rodents) BAT was increased by $100 \%(\mathrm{P}<0.05)$ in adult male rats that were fed a high carbohydrate diet as compared to rats fed an equicaloric high fat diet (Glick et al. 1984). Blood flow was measured because it can be highly correlated with its thermogenic activity and this study indicated that high carbohydrate diets are more thermogenic than high fat diets. It has also been determined that adult rats fed high amounts of essential fatty acids are in a state of decreased metabolic efficiency (low weight gain) and have a doubled expression of UCPl (g/body weight) indicating that increased fatty acids are affecting the efficiency of BAT 
thermogenesis (Nedergaard et al. 1983). These results are expected as fatty acids play a crucial role in non-shivering thermogenesis, inhibiting purine nucleotides to allow proton movement through $U C P 1$. Using data gained from these experiments, novel research involving L-arginine supplementation has become an area of great interest because of its involvement in nitric oxide production, a potent blood stimulator. One study using adult male Zucker diabetic fatty rats supplemented with $0.2 \%$ L-arginine or $63 \%$ watermelon pomace juice, high in citrulline which is a precursor for arginine, in their drinking water resulted in increased BAT mass $(\mathrm{P}<0.05) \quad(\mathrm{Wu}$ et al. 2007). A different study used adult male rats that were fed a high fat or low fat diet with $1.51 \% \mathrm{~L}$ arginine supplemented in the drinking water which resulted in a $34 \%$ increase in BAT mass (Jobgen et al. 2009). The increased BAT mass that resulted from L-arginine administration may be due to increased blood flow to the tissue. While these studies did not research the effects of L-arginine supplementation on neonatal thermogenesis or cold stress resistance, they did indicate that L-arginine supplementation may be a way to increase BAT mass and potentially increase thermogenic capacity in newborns by increasing blood flow to the tissue.

In cattle, several studies have shown that nutrient restriction during gestation has detrimental effects on calf birth weight, survivability, and thermogenic capacity (Corah et al. 1975; Warrington et al. 1988). Interestingly, several studies have shown that over nutrition using a high fat diet during gestation resulted in calves with a greater resistance to cold stress. One such study showed that feeding beef females supplemental fat during gestation resulted in increased glucose concentrations leading to favorable responses in 
body temperature of the newborn calves (Lammoglia et al. 1999b). Another study subjected newborn calves to a cold challenge at $0^{\circ} \mathrm{C}$ for 140 minutes and calves born from dams fed a high fat diet (5.1\%) had higher rectal temperatures than the calves born from the control dams (Lammoglia et al. 1999a). However, while fat supplementation may increase neonatal thermogenesis, the long term effects of a high fat diet during gestation must be taken into consideration. In humans, adipocyte development in the fetus begins in mid gestation and the number of adipocytes is determined during childhood and changes minimally through adulthood (Spalding et al. 2008). If the number of adipocytes is set during childhood, it can be assumed that adipocyte number set during fetal development plays a crucial role in the amount of fat accumulation in adulthood (Satterfield et al. 2010). Knowing the important role of epigenetic changes and fetal programming during fetal development, it is possible that alterations made in utero could provide significant changes to the fetus and multiple generations. The observation that calves also had higher circulating concentrations of glucose at all time points in the Lammoglia et al. (1999a) study may indicate that glucose tolerance and insulin sensitivity is altered in these animals. Impaired glucose tolerance and insulin sensitivity may contribute to increased adiposity and decreased efficiency of growth, as observed in other mammalian species (Cerf et al. 2006; Cerf et al. 2005; Ford et al. 2009; Long et al. 2010; Shiell et al. 2000; Srinivasan et al. 2006; Yan et al. 2011; Zhang et al. 2011). These studies indicate that high fat diets in cattle could be a potential way to enhance neonatal thermogenesis in a large scale production setting, however the long term effects need to be carefully considered. 
Since it was discovered that BAT mass could be increased, more research began to focus on the potential effects of increased BAT to increase cold tolerance. One study in sheep determined the effects of cold stress on neonatal thermogenesis by inducing cold stress to the mothers. This was carried out by ewes being sheared 4 weeks before their predicted lambing date (Clarke et al. 1997). Lambs born from these mothers had increased mitochondrial protein and higher total thermogenic activity in BAT indicating that the activity of BAT thermogenesis is partly affected by the conditions the encounters while pregnant. Also, based on the observation that supplemental fat administration during gestation in cattle can enhance newborn calves' response to cold, a study by Chen et al. (2007) researched the effects of fat supplementation in gestating ewes. This study supplemented gestating ewes with 2,4 , or $8 \%$ polyunsaturated fatty acid (PUFA) or saturated and monounsaturated fatty acids (SMFA) and then subjected the newborn lambs to cold stress $\left(0^{\circ} \mathrm{C}\right.$ for 2 hours) (Chen et al. 2007). They hypothesized that lambs born from mothers receiving the $8 \%$ supplemental fat would have the greatest thermogenesis. Interestingly, BAT from lambs of the 2 or $4 \%$ PUFA treated mothers had a 7-fold increase in UCP1 mRNA expression than lambs from ewes fed $8 \%$ PUFA. Unexpectedly, lambs of the $8 \%$ PUFA treated mothers resulted in decreased thermogenesis due to compromised mitochondrial oxidation of fatty acids indicating that over administration of fatty acids may have detrimental effects on thermogenesis. Surprisingly, increased maternal nutrition in sheep results in less BAT per kg of body weight, but increased UCPI abundance, suggesting that over nutrition may be altering brown adipocyte characteristics (Budge et al. 2000). Another study 
found that parenteral L-arginine infusion to gestating ewes, being fed $50 \%$ of their recommended nutrition and ad libitum from day 100 to day 125 resulted in a $62 \%$ and $60 \%$ increase in fetal peri-renal BAT respectively, further confirming that L-arginine is capable of increasing BAT mass in both undernourished and overnourished ewes (Figure 2.5) (Satterfield et al. 2009).

The above research, summarized in Table 2.2, shows the interesting effects of arginine supplementation as well as different effects of maternal nutrition on BAT and thermogenesis. Nutritional manipulation of BAT and thermogenesis would be the most practical way to achieve results in a production setting and much more research is needed in this field to determine a supplement that is capable of increasing cold tolerance in newborn animals.

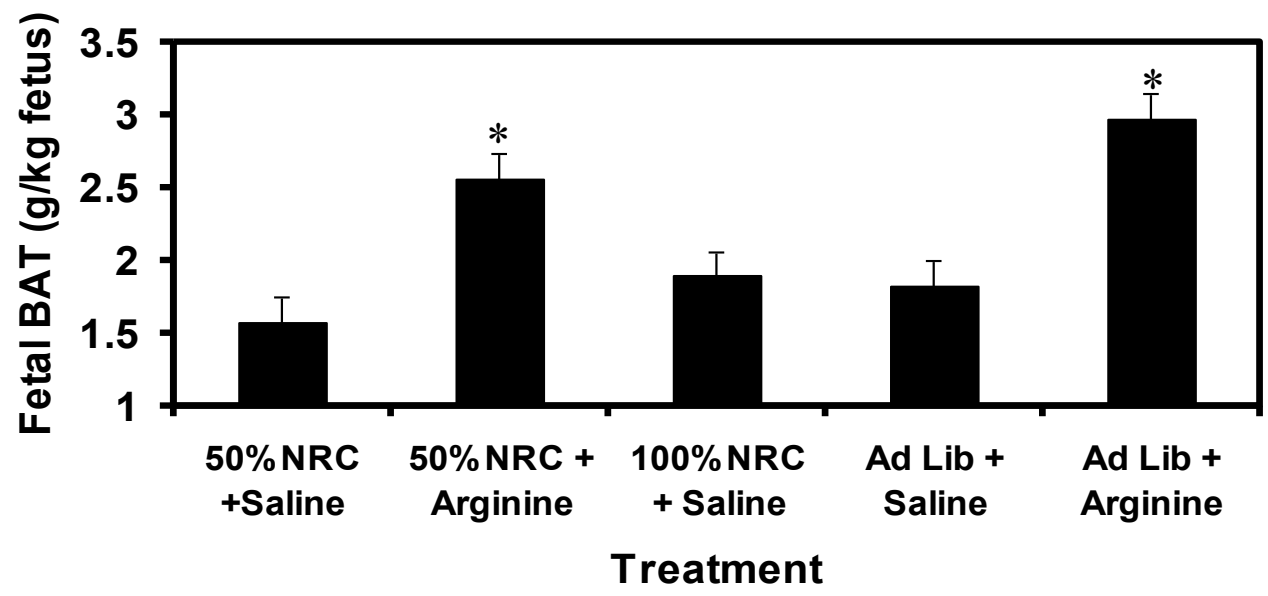

Figure 2.5. Effects of maternal nutrition on fetal BAT weight. Gestating ewes fed either $50 \%$ of NRC-recommended nutrient requirements between Days 35 and 125 of gestation, or ad libitum from three months before the estrous cycle and between Days 0 and 125 of gestation resulted in fetuses with a $62 \%$ and $60 \%$ increase in fetal perirenal BAT respectively (Satterfield et al. 2009). 
TABLE 2.2. Summary of nutritional manipulations to enhance BAT and/or thermogenic capacity.

\begin{tabular}{|c|c|c|c|}
\hline Species & Modification of BAT or Cold tolerance & Result & Reference \\
\hline Rat & $\begin{array}{l}\text { Adult male rats fed high amount of essential } \\
\text { fatty acids }\end{array}$ & $\begin{array}{l}\text { Lower weight gain and } \\
\text { doubled expression of } \\
\qquad U C P 1\end{array}$ & Nedergaard et al. 1983 \\
\hline Rat & Adult male rats fed high carbohydrate diet & $\begin{array}{l}\text { Blood flow to scapular } \\
\text { BAT increased by } \\
100 \%\end{array}$ & Glick et al. 1984 \\
\hline Rat & $\begin{array}{c}\text { Drinking water containing } 0.2 \% \mathrm{~L} \text {-arginine or } \\
63 \% \text { watermelon pomace juice }\end{array}$ & $\begin{array}{c}\text { Increased BAT mass } \\
(\mathrm{P}<0.05) \text { in rats from } \\
\text { both treatments }\end{array}$ & Wu et al. 2007 \\
\hline Rat & $\begin{array}{l}\text { Rats fed high fat and low fat diets with } 1.51 \% \\
\text { L-arginine supplemented in drinking water }\end{array}$ & $\begin{array}{c}\text { Arginine treatment } \\
\text { increased BAT mass } \\
\text { by } 34 \% \\
\end{array}$ & Jobgen et al. 2009 \\
\hline Ovine & $\begin{array}{c}\text { Gestating ewes sheared } 4 \text { weeks before lambing } \\
\text { date }\end{array}$ & $\begin{array}{l}\text { Lambs had more } \\
\text { mitochondrial protein } \\
\text { and exhibited higher } \\
\text { total thermogenic } \\
\text { activity in BAT }\end{array}$ & Clarke et al. 1999 \\
\hline Ovine & $\begin{array}{c}\text { Gestating ewes supplemented with } 2,4 \text {, or } 8 \% \\
\text { PUFA or SMFA }\end{array}$ & $\begin{array}{c}8 \% \text { SMFA } \\
\text { compromised } \\
\text { thermogenesis }\end{array}$ & Chen et al. 2006 \\
\hline Ovine & $\begin{array}{l}\text { Gestating ewes administered L-arginine from } \\
\text { day } 100 \text { to day } 125 \text { of gestation }\end{array}$ & $\begin{array}{c}\text { Fetal peri-renal BAT } \\
\text { mass in day } 125 \\
\text { fetuses increased by } \\
62 \% \\
\end{array}$ & Satterfield et al. 2009 \\
\hline Bovine & Gestating beef females fed high fat diet & $\begin{array}{l}\text { Newborns had higher } \\
\text { rectal temperatures } \\
\text { when subjected to cold }\end{array}$ & Lammoglia et al. 1999a \\
\hline Bovine & $\begin{array}{l}\text { Gestating beef females fed supplemental fat } \\
\text { from day } 230 \text { to term }\end{array}$ & $\begin{array}{c}\text { Increased cold } \\
\text { tolerance in newborn } \\
\text { calves }\end{array}$ & Lammoglia et al. $1999 \mathrm{~b}$ \\
\hline
\end{tabular}




\section{BAT AND ARGININE: SIGNALING POSSIBILITIES}

An important factor in BAT formation, vascularization, and function is arginine. Arginine is a conditionally essential amino acid, meaning that dietary supplementation is only needed during certain physiological states, such as pregnancy, cold stress, or metabolic disorder. Arginine has been shown to improve spermatogenesis, embryonic survival, immune functions, cardiovascular function, and reproductive function (Wu et al. 2009). Recently, arginine administration to ewes from day 100-121 of gestation resulted in a $23 \%$ decrease in number of lambs born dead, a $59 \%$ increase in number of lambs born alive, and a $23 \%$ increase in birth weights of lambs born from mothers carrying multiple fetuses (Lassala et al. 2011). This data indicates that arginine administration during gestation may be a way to enhance neonatal survivability and birth weight and could possibly increase fetal BAT growth as well. The exact mechanisms of how arginine is affecting BAT in the rat and neonatal lamb remains unknown. There are three proposed pathways that are hypothesized to be involved that can be summarized in Figure 2.6. 


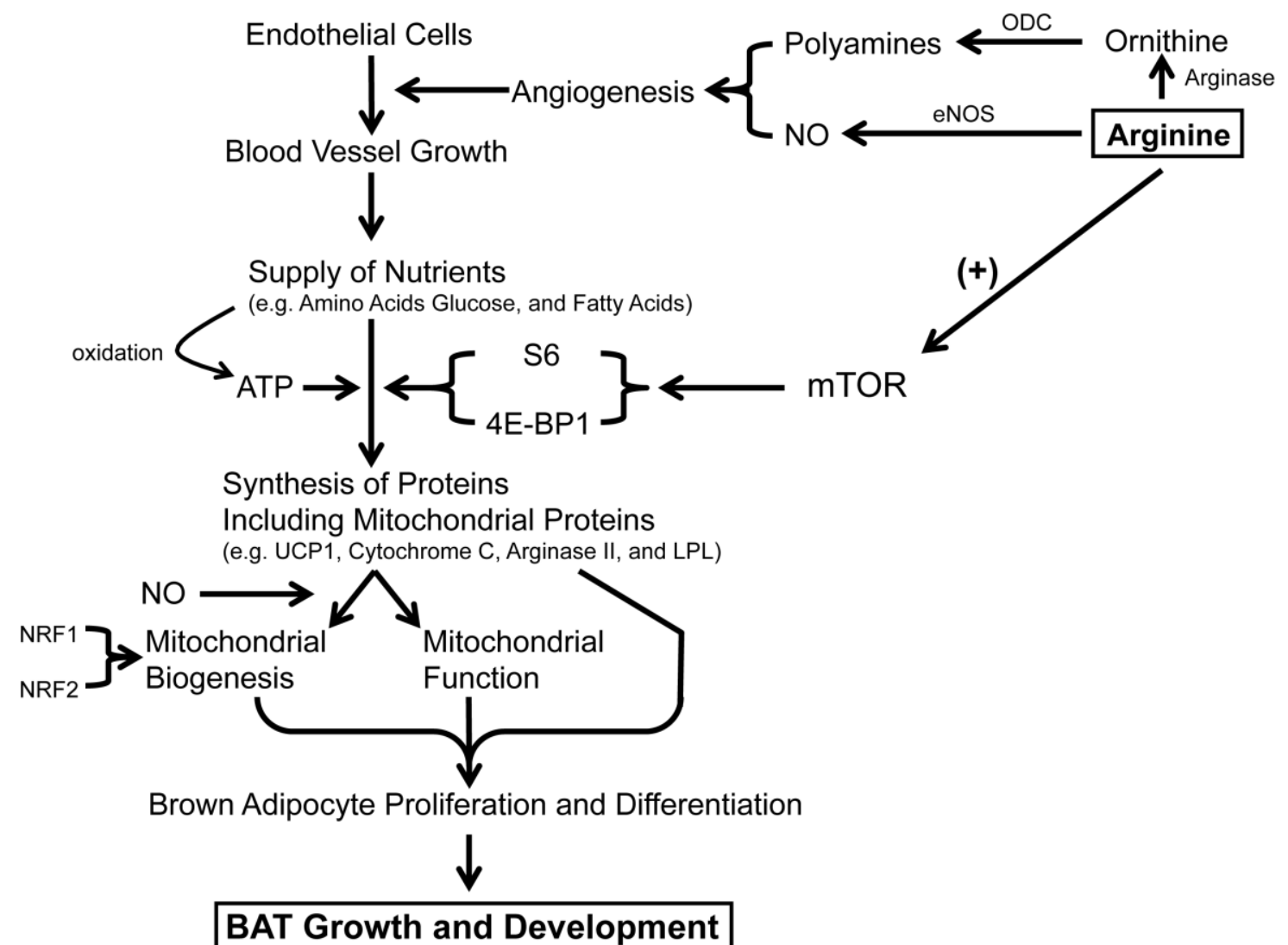

Figure 2.6. Proposed mechanism of arginine involvement in BAT growth and development. Arginine is the common substrate for NO and polyamine synthesis, which are both essential for angiogenesis. With increased angiogenesis, nutrient supply of amino acids, glucose, fatty acids also increases. Increased nutrient supply through the circulation allows for increased oxidation to provide more energy (ATP and heat). Arginine may also activate mTOR/FRAP1 resulting in S6 and 4E-BP1 phosphorylation. This cascade of events can enhance the synthesis of proteins including mitochondrial proteins such as UCPI and others that are essential for mitochondrial biogenesis. Mitochondrial biogenesis is also regulated by NO and controlled by NRF1 and NRF-2 (transcription factors). All of these pathways ultimately lead to enhanced brown adipocyte proliferation and differentiation and increased BAT growth and development Satterfield and $\mathrm{Wu} 2011$.

The first hypothesized mechanism by which L-arginine may be affecting BAT is through nitric oxide (NO). Nitric oxide is a signaling molecule that regulates nutrient metabolism and is produced from L-arginine by NO synthase (NOS) in almost all cell 
types and tissues including adipocytes (Jobgen et al. 2006). Nitric oxide is a key endothelium-derived relaxing factor, modulator of immune responses, neurotransmitter, widespread signaling molecule in the body, and is involved in mitochondrial biogenesis and angiogenesis (Flynn et al. 2002). Nitric oxide is also involved in regulating vascular tone and homeostasis (Alderton et al. 2001; Shi et al. 2004). Studies have shown that brown adipocytes express isoforms of NO synthase (eNOS and iNOS) and that NO produced by these isoforms is directly involved in BAT function and regulation (Kikuchi-Utsumi et al. 2001; Nisoli et al. 2003; Nisoli et al. 1997). Interestingly, the involvement of NO in mitochondrial biogenesis and angiogenesis is well understood in WAT as it is important for regulating blood flow and increasing the supply of metabolic substrates and oxygen to mitochondria (Jobgen et al. 2006). It is hypothesized to have a similar role in BAT because of the increased amount of mitochondria in the tissue. Because NO has been shown to have beneficial effects on mitochondrial proliferation and activation, it can be named a key regulator of cell metabolism as its actions are coordinated to meet the energy demands of the cell (Nisoli et al. 2003). Mitochondrial biogenesis stimulation by NO is also accompanied by marked increases in cGMP, PPARGC1A, NRF1 and mitochondrial transcription factor A (mtTFA), which can be summarized in figure 2.7 (Brown 2007). The role of NO can be further understood through studies involving NO synthase knockout mice. Research using eNOS knockout mice resulted in mice with lower levels of mitochondria in many tissues indicating that NO is closely involved in regulating mitochondrial density in tissues (Nisoli et al. 2003). Nitric oxide also regulates blood flow to BAT following noradrenergic stimulation and 
is involved in differentiation and proliferation (Nisoli et al. 1998). These mice also exhibited reduced mitochondrial biogenesis within BAT in response to cold exposure, reduced metabolic rate, and increased weight gain (Nisoli et al. 2003). Interestingly, the effects of complete inhibition of NO synthesis by N-omega-nitro-L-arginine methyl ester (L-NAME), which include reduced BAT blood flow, can be reversed by L-arginine supplementation. Furthermore, increased thermogenesis in response to norepinephrine is also inhibited by L-NAME, indicating that NO is directly involved in the increased BAT blood flow cause by norepinephrine release (Nagashima et al. 1994). In a recent study, cold acclimated adult male rat treated with L-arginine showed an increase in iNOS levels and interscapular BAT (Petrovic et al. 2005). This discovery further validates the theory that L-Arginine supplementation can be used to enhance BAT function and growth. The effects of L-arginine have also been studied in humans, pigs, rats, and sheep in which Larginine has been supplemented to mothers during pregnancy. A recent study in sheep that involved intravenous supplementation of L-arginine concluded that pre-natal arginine supplementation increased fetal peri-renal BAT mass in day 125 fetuses by $62 \%$ (Satterfield et al. 2009). Research in rats has also shown similar results with a $25 \%$ increase of interscapular BAT in rat pups (Satterfield 2010 unpublished data). This is an extremely significant and novel discovery as it may be used as a way to increase thermogenic capacity in newborns and increase survivability. Using what is known about NO and its involvement in mitochondrial biogenesis and vascularization, it is reasonable to hypothesize that NO is directly involved in BAT growth and function and increasing NO through arginine supplementation may enhance the effects of BAT. 


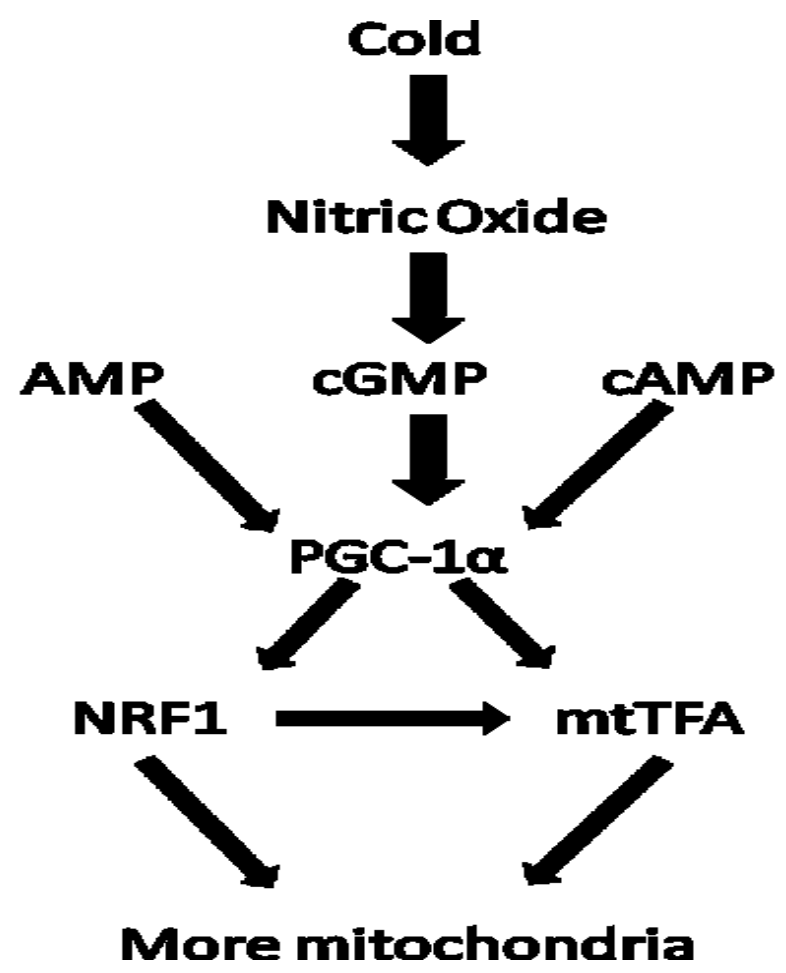

Figure 2.7. Possible roles of nitric oxide in mitochondrial biogenesis. Exercise, cold exposure, and caloric restriction may activate $\mathrm{NO}$ production that may increase PPARGC1A expression via cGMP. PPARGC1A leads to an increase in mitochondrial biogenesis by promoting other mitochondrial genes, NRF1 and mtTFA. Adapted from (Brown 2007).

Another way in which arginine may be affecting BAT development and function is through the FKBP12-rapamycin complex associated protein 1 (FRAP1 also known as mTOR) (Yao et al. 2008). L-arginine is a mediator of many metabolic pathways for nutrient utilization and protein synthesis through mTOR and NO cell signaling pathways (Jobgen et al. 2006). This signaling cascade is involved in regulation of protein synthesis, cell growth and proliferation, cell motility, and cell survival (Beevers et al. 2006; Hay and Sonenberg 2004). Signaling through mTOR directly targets eukaryotic 
initiation factor 4E-binding protein-1 (4E-BP1) and ribosomal protein S6 kinase 1 (S6K1) (Thomson et al. 2008). In a recent study, it has been shown that dietary supplementation of L-arginine altered the phosphorylation of 4E-BP1, reducing the inactive form of the protein and increasing formation of the active form in skeletal muscle (Yao et al. 2008). L-arginine has been shown to activate the mTOR signaling cascade through increased phosphorylation of 4E-BP1 and S6K1 (Kim et al. 2011). As part of the mTOR pathway, 4E-BP1 and S6K1 are involved in protein synthesis of many proteins such as mitochondrial proteins, leading to increased mitochondrial biogenesis and function. L-arginine has been shown to be an activator of mTOR/FRAP1 and could possibly be acting independently of NO through this pathway (Yao et al. 2008).

The third possible mechanism of arginine involvement in BAT is through the synthesis of polyamines. L-arginine is a substrate of polyamine synthesis and is converted to ornithine via arginase and then to polyamines via ornithine decarboxylase (ODC1) (Flynn et al. 2002). Polyamines are responsible for regulating DNA and protein synthesis and thus regulate cell proliferation and differentiation (Flynn et al. 2002). Like NO, polyamines are also extensively involved in angiogenesis, as well as placental and fetal growth (Wu et al. 2004; Wu and Morris 1998). As vascularization of BAT is critical for substrate acquisition and heat production, it can be hypothesized that angiogenesis stimulated by polyamines may be playing a crucial role in fetal BAT development and function. 
The role of polyamines in BAT can be further understood by examining studies in which polyamine synthesis has been inhibited in rats. Inhibition of polyamine synthesis results in impaired embryogenesis, and placental polyamine synthesis inhibition results in reduced placental size and impaired fetal growth (Ishida et al. 2002). These results indicate that polyamines are closely involved in fetal growth and could also be playing a role in BAT growth and development.

Low birth weight newborns have decreased fat stores and are not able to maintain a core body temperature efficiently and arginine may be a way to reduce this problem. It is interesting to note that maternal arginine deficiency results in low birth weight offspring and increases fetal resorption and death and that maternal arginine supplementation reverses these effects in rat models, indicating that arginine supplementation is an effective way of providing adequate polyamine synthesis and therefore enhancing angiogenesis and BAT growth and development (Vosatka et al. 1998). The role of polyamines and arginine supplementation, as regulated by maternal nutrition, can be summarized in Figure 2.8. 


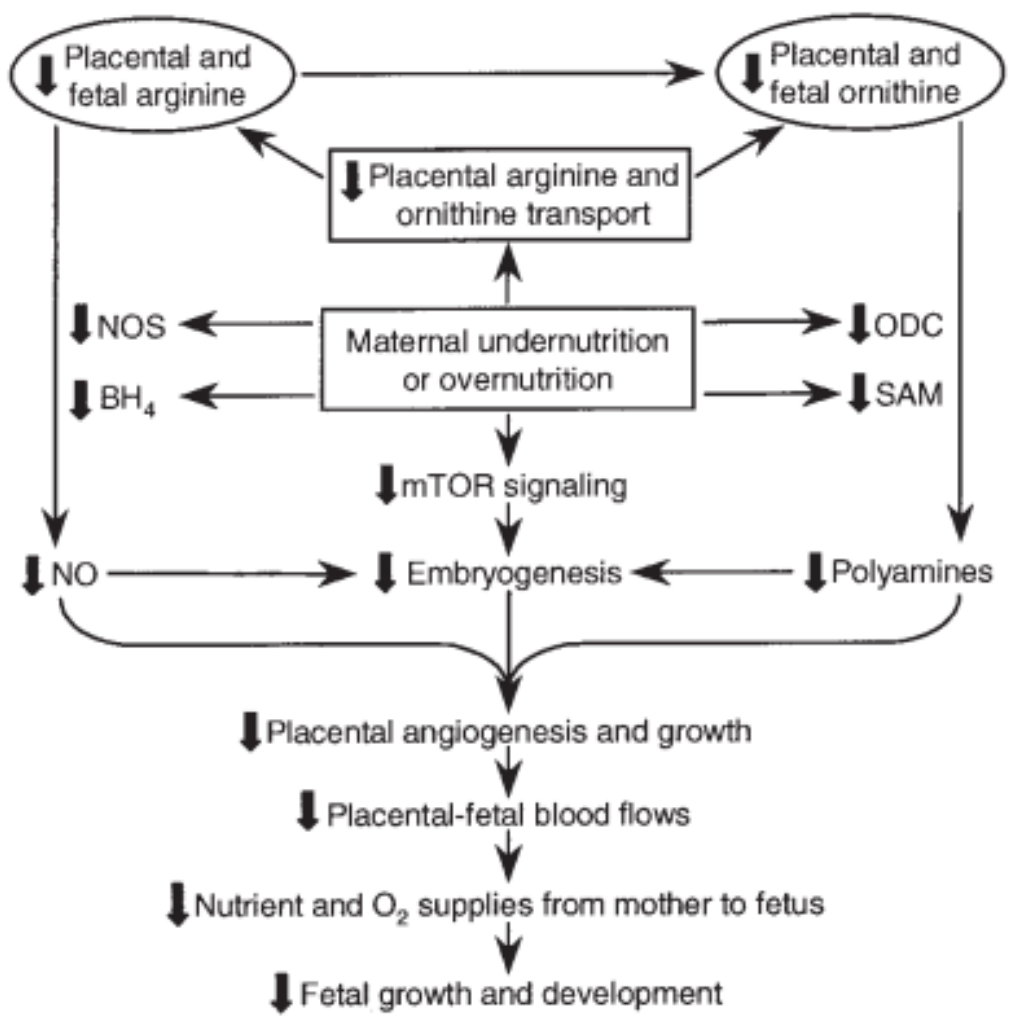

Figure 2.8. Proposed role of polyamines and arginine supplementation as regulated by maternal nutrition. It is important to note that both maternal undernutrition and overnutrition may have detrimental effects on fetal growth and development, both leading to reduced placental angiogenesis and growth (Wu et al. 2004).

\section{SUMMARY AND OBJECTIVES}

BAT is essential for neonatal survival because of its remarkable ability to help newborns regulate their core body temperature through non-shivering thermogenesis following parturition. With $40 \%$ of non-predator related lamb deaths and approximately 95,000 calves dying annually because of cold stress and cold related losses, such as starvation due to hypothermia, finding ways to increase thermogenic capacity in newborns is a crucial step to increasing survivability. An effective way to increase BAT 
growth has been shown through L-arginine supplementation in several studies involving sheep and rats. Brown adipose tissue is an extremely valuable source for new research involving neonatal thermogenesis and has the potential to solve many problems in human and animal health. This study utilized an ovine model to focus on the following objectives:

1. Clarify mechanisms for improved BAT growth and development in fetal lambs of ewes receiving intravenous infusion of arginine.

2. Study the physiological response to cold stress in newborn lambs whose mothers had received supplemental arginine during late gestation.

\section{HYPOTHESIS}

The overall goal of this research is to increase lamb survivability through increased thermogenic capacity. The working hypothesis is that arginine supplementation increases fetal BAT growth and development which, in turn, will increase thermogenic response to cold. Prenatal supplementation of arginine to the mother will increase growth and development of this vital tissue to help the lamb adapt to the cold environment after birth. 


\section{CHAPTER III}

\section{A NOVEL ROLE FOR ARGININE IN ENHANCING NEONATAL THERMOGENESIS}

Cold-weather related losses, including starvation due to hypothermia, make up approximately $40 \%$ of the total lamb deaths (Simpson 1995). In many animals, including sheep, neonatal survival depends on the generation of heat by brown adipose tissue (BAT) to maintain core body temperature. Expulsion of the fetus from the temperature controlled intrauterine environment to an often harsh extrauterine environment is the first obstacle that the newborn is exposed to and must adapt in a matter of minutes to ensure survival (Clarke et al., 1998). Infant mortality rates increase significantly when exposed to even short periods of hypothermia (Satterfield and $\mathrm{Wu}$ 2011). The production of heat by BAT is achieved by a process called non-shivering thermogenesis, which is under adrenergic control of the sympathetic nervous system. Unfortunately, the ability of this tissue to create heat through non-shivering thermogenesis deteriorates rapidly during the first weeks following parturition because the BAT is metabolized and subsequently replaced by white adipose tissue (WAT) (Symonds et al., 1992). Adipose tissue development is one of the most important processes that occurs during the development of a mammalian fetus. Non-shivering thermogenesis is specific to BAT and allows for heat generation from within the body. The capacity to generate large quantities of heat is unique to BAT and results from the large number of mitochondria present in BAT and the high abundance of the BAT- 
specific protein uncoupling protein 1 (UCP1). These features of BAT allow it to produce 150-300 times more heat per gram of tissue than other bodily tissues (Power 1989). BAT metabolism for non-shivering thermogenesis accounts for approximately $50 \%$ of the heat generated in the newborn lamb. This is a remarkable characteristic as BAT accounts for only about $2 \%$ of the body weight at birth (Symonds et al., 1992). Given its importance, the ability to increase BAT development and/or function is an important step to improve lamb survivability.

An important factor in BAT formation, vascularization, and function is arginine. Arginine is a conditionally essential amino acid, meaning dietary supplementation is only needed during certain physiological states, such as pregnancy, cold stress, or metabolic disorder (Flynn et al. 2002). Importantly, arginine exerts beneficial effects on spermatogenesis, embryonic survival, fetal and neonatal growth, immune functions, cardiovascular function, and reproductive function (Wu et al. 2009). Arginine is synthesized from citrulline via arginosuccinate and is the precursor to nitric oxide (NO), an important signaling molecule and vasodilator that regulates nutrient metabolism in almost all cell types and tissues including adipocytes, brain, endothelial cells, heart, macrophages, and skeletal muscle (Jobgen et al. 2006). In a previous we found that maternal parenteral supplementation of arginine from days 100 to 125 of gestation increased fetal peri-renal BAT growth by 62\% (Satterfield et al. 2009). An increase in BAT mass is hypothesized to improve the newborn lambs' ability to maintain core body temperature in response to cold stress. Therefore, the purpose of this study was to 
enhance thermogenic capacity of the neonate in response to cold through maternal intravenous administration of L-arginine.

\section{RESULTS}

\section{Rectal Temperatures of Lambs during 2-Hour Cold Challenge}

Temporal changes in rectal temperature following cold challenges 1 and 2 are presented in Figure 3.1. Beginning at 4 hours of age and continuing throughout the 2 hour cold challenge, rectal temperature of lambs born to arginine-treated ewes was higher $(\mathrm{P}<0.05)$ than rectal temperature of lambs born to saline-treated ewes. Similar to results from cold challenge 1 , rectal temperatures of lambs at 22 hours of age and continuing throughout the second cold challenge were higher $(\mathrm{P}<0.05)$ in lambs from arginine- versus saline-treated ewes. As expected, rectal temperature of all lambs increased $(\mathrm{P}<0.01)$ sharply within 15 minutes of the initiation of the respective coldchallenges and declined gradually throughout the challenges. 

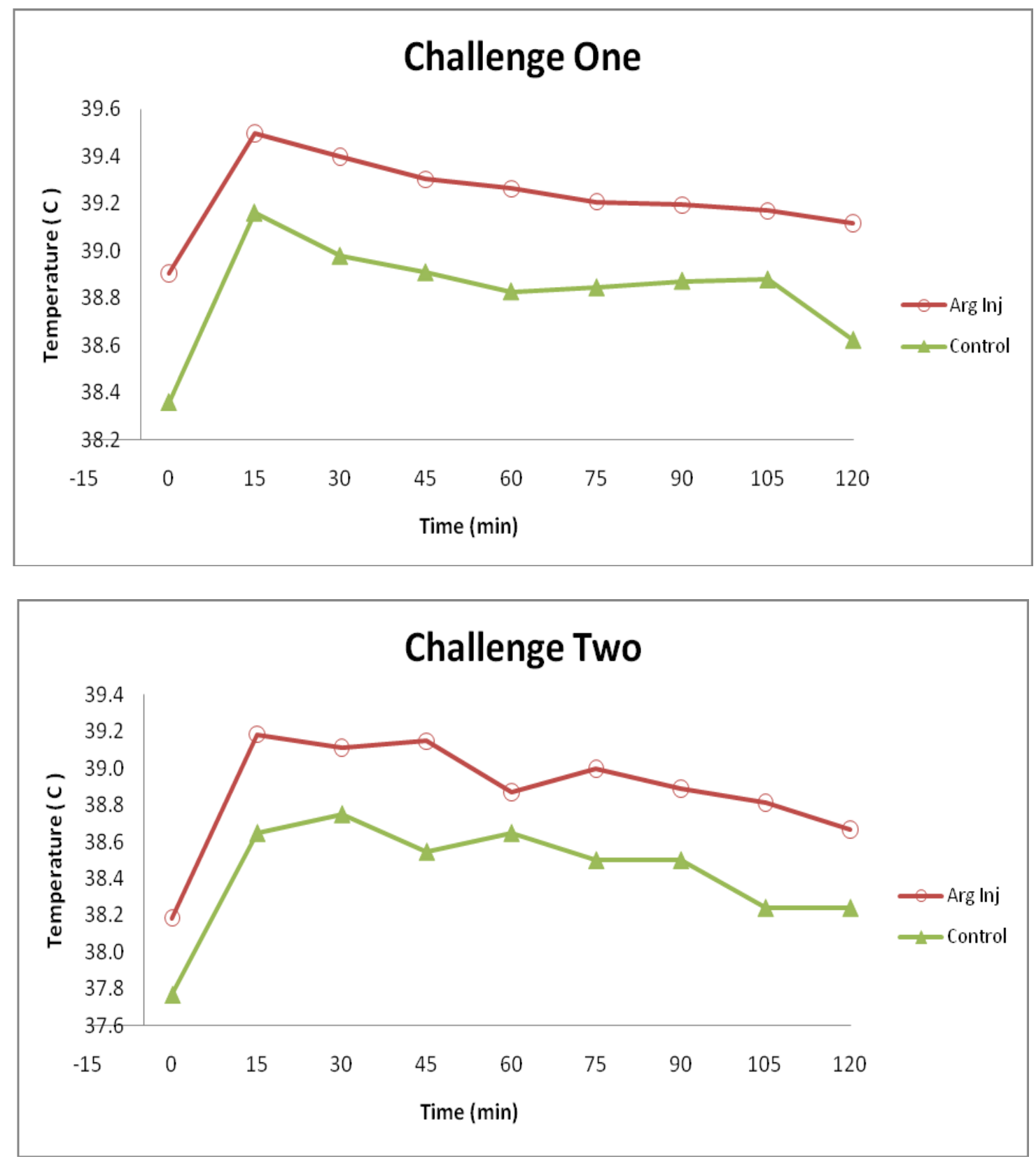

Figure 3.1. Neonatal lamb body temperature during a 2-hour cold challenge at $0^{\circ} \mathrm{C}$. During both challenges, lambs born from L-arginine treated mothers $(n=22)$ had higher rectal temperatures at the beginning of each challenge and maintained the higher temperature throughout the entire challenge than lambs born from saline treated mothers $(\mathrm{n}=20)(\mathrm{P}<0.05)$. Rectal temperature of all lambs increased $(\mathrm{P}<0.01)$ sharply within 15 minutes of the initiation of the respective cold-challenges and declined gradually throughout the challenges. 


\section{Biochemical Analysis of Lamb Plasma}

Quantification of circulating plasma concentrations of norepinephrine at $0,4,6$, 22 , and 24 hours of age revealed no difference $(\mathrm{P}>0.10)$ between treatment groups or by age $(\mathrm{P}>0.05)$. There was no difference $(\mathrm{P}>0.10)$ in plasma concentrations of free fatty acids (FFA) between lambs from arginine-treated versus saline-treated ewes. However, FFA concentrations declined $(\mathrm{P}<0.0001)$ from 0 hour of age to all subsequent ages. At 22 and 24 hours of age plasma FFA concentrations were further reduced $(\mathrm{P}<0.0001)$ as compared to FFA concentrations at 4 and 6 hours of age, irrespective of treatment. Plasma glucose concentration did not differ $(\mathrm{P}<0.10)$ between lambs from saline and arginine-treated ewes, however glucose concentrations increased $(\mathrm{P}<0.0001)$ from 0 to 4 and again to 6 hours of age before declining at 22 and 24 hours of age. Results from FFA, glucose, and norepinephrine plasma level determination can be summarized in Table 3.1. 
TABLE 3.1. Lamb plasma concentrations of free fatty acids, glucose, and norepinephrine at $0,4,6,22,24$ hours of age.

\begin{tabular}{|c|c|c|c|c|c|c|c|c|c|c|c|}
\hline & \multicolumn{2}{|c|}{ Treatment } & \multicolumn{5}{|c|}{ Age (hours) } & \multirow[b]{2}{*}{ SE } & \multirow[b]{2}{*}{ Trt } & \multirow[b]{2}{*}{ Age } & \multirow{2}{*}{$\begin{array}{c}\text { Age } X \\
\text { Trt }\end{array}$} \\
\hline & $\begin{array}{c}\text { Arginine } \\
(n=22)\end{array}$ & $\begin{array}{l}\text { Control } \\
(n=20)\end{array}$ & 0 & 4 & 6 & 22 & 24 & & & & \\
\hline FFA (mEq/L) & 0.541 & 0.495 & $0.774^{\mathrm{a}}$ & $0.636^{\mathrm{b}}$ & $0.622^{\mathrm{b}}$ & $0.248^{c}$ & $0.309^{c}$ & 0.1 & n.s. & $P<0.0001$ & n.s. \\
\hline Glucose (mM) & 4.29 & 3.71 & $3.30^{\mathrm{c}}$ & $4.79^{b}$ & $6.06^{\mathrm{a}}$ & $2.77^{\mathrm{c}}$ & $3.29^{b c}$ & 0.81 & n.s. & $P<0.0001$ & n.s. \\
\hline $\begin{array}{l}\text { Norepinephrine } \\
\quad(\mathrm{ng} / \mathrm{ml})\end{array}$ & 1.273 & 1.235 & 1.207 & 1.176 & 1.314 & 1.23 & 1.353 & 0.14 & n.s. & n.s. & n.s. \\
\hline
\end{tabular}

Means in a row with superscripts without a common letter differ, $\mathrm{P}<0.05$ with regard to effects of age. 


\section{BAT Weight and Cellular Content due to Arginine Treatment}

Cellular composition of peri-renal BAT is outlined in Table 3.2. Post-challenge necropsy of lambs at 6 hours of age revealed that peri-renal BAT mass was not different $(\mathrm{P}>0.10)$ between lambs born to saline- or arginine-treated ewes. However, BAT weight was reduced $(\mathrm{P}<0.0001)$ in lambs sacrificed at 24 hours of age as compared to 6 hours of age, irrespective of maternal treatment. Analysis of BAT lipid content revealed no difference $(\mathrm{P}>0.10)$ in percent lipid within peri-renal BAT in response to maternal arginine treatment, however, lipid content was lower $(\mathrm{P}<0.0001)$ in peri-renal BAT at 24 hours of age as compared to 6 hours of age. Total protein content of peri-renal BAT did not differ $(\mathrm{P}>0.10)$ in response to treatment or by age. In contrast, total mitochondrial protein in BAT was increased $(\mathrm{P}<0.01)$ in lambs at 24 hours of age as compared to lambs at 6 hours of age, but was not affected $(\mathrm{P}>0.10)$ by arginine supplementation.

\section{BAT Oxidation and Protein Synthesis}

Metabolism of glucose, amino acids, and fatty acids by BAT are presented in Table 3.3. BAT oxidation of glucose, leucine, glutamine, and oleic acid was not different in lambs born to saline or arginine-treated ewes, however oleic acid oxidation was greater $(\mathrm{P}<0.05)$ in lambs at 24 hours age as compared to lambs at 6 hours of age irrespective of maternal treatment. There was no difference $(\mathrm{P}>0.10)$ in BAT protein synthesis in response to increasing doses of arginine treatment (data not shown). 


\section{Histological Analyses of BAT}

Histological analysis of BAT supports previous compositional analyses. H\&E staining indicates that there was no difference in BAT gross morphology between lambs born to saline or arginine-treated ewes, however a reduction in the number and/or size of the lipid droplets was observed in BAT collected at 24 hours of age as compared to BAT collected at 6 hours of age (Figure 3.2). There was also no difference in VWF protein (Figure 3.3), an endothelial specific marker, between treatments or by age. Similarly, there was no difference in the number of Ki-67 positively staining nuclei between treatments or by age (Figure 3.4). Ki-67 is a marker of cellular proliferation. Finally, there was no difference in UCP1 (Figure 3.5) or VDAC (Figure 3.6) protein expression by treatment or by age. These proteins are mitochondrial proteins that serve as the primary functional unit of BAT and as a mediator of energy metabolism, respectively.

TABLE 3.2. Effect of arginine treatment, age, and their interaction on BAT weight and cellular content.

\begin{tabular}{|c|c|c|c|c|c|c|c|c|}
\hline & \multicolumn{2}{|c|}{6 Hours } & \multicolumn{2}{|c|}{24 Hours } & \multirow[b]{2}{*}{ SE } & \multirow[b]{2}{*}{ Trt } & \multirow[b]{2}{*}{ Age } & \multirow[b]{2}{*}{$\begin{array}{l}\text { Trt X } \\
\text { Age }\end{array}$} \\
\hline & $\begin{array}{l}\text { Saline } \\
(\mathrm{n}=14)\end{array}$ & $\begin{array}{c}\text { Arginine } \\
(\mathrm{n}=18)\end{array}$ & $\begin{array}{l}\text { Saline } \\
(\mathrm{n}=6)\end{array}$ & $\begin{array}{c}\text { Arginine } \\
(\mathrm{n}=4)\end{array}$ & & & & \\
\hline $\begin{array}{l}\text { BAT Weight } \\
(\mathrm{g})\end{array}$ & 17.9 & 18.9 & 11.2 & 13.9 & 1.2 & n.s. & $\mathrm{P}<0.0001$ & n.s. \\
\hline $\begin{array}{c}\text { Lipid Content } \\
(\%)\end{array}$ & 29.7 & 30.3 & 19.9 & 18.4 & 2.5 & n.s. & $\mathrm{P}<0.001$ & n.s. \\
\hline $\begin{array}{c}\text { Protein } \\
\text { Content } \\
\text { (mg/g tissue) }\end{array}$ & 373 & 373 & 292 & 383 & 31 & n.s. & n.s. & n.s. \\
\hline $\begin{array}{l}\text { Mitochondrial } \\
\text { Protein } \\
\text { Content } \\
\text { (mg/g tissue) }\end{array}$ & 42.3 & 48.2 & 56.8 & 59.1 & 4.8 & n.s. & $\mathrm{P}<0.01$ & n.s. \\
\hline
\end{tabular}


Table 3.3. BAT oxidation of leucine, oleic acid, glucose, and glutamine.

\begin{tabular}{|c|c|c|c|c|c|c|c|c|}
\hline & \multicolumn{2}{|c|}{ Treatment } & \multicolumn{2}{|c|}{ Age (hours) } & \multirow[b]{2}{*}{ SE } & \multirow[b]{2}{*}{ Trt } & \multirow[b]{2}{*}{ Age } & \multirow{2}{*}{$\begin{array}{c}\text { Age } X \\
\text { Trt }\end{array}$} \\
\hline & $\begin{array}{c}\text { Arginine } \\
(n=22)\end{array}$ & $\begin{array}{l}\text { Control } \\
(n=20)\end{array}$ & $\begin{array}{c}6 \\
(n=32)\end{array}$ & $\begin{array}{c}24 \\
(n=10)\end{array}$ & & & & \\
\hline $\begin{array}{c}\text { Leucine } \\
\text { (nmol/2hr } \\
\text { per g tissue) }\end{array}$ & 531 & 1292 & 1058 & 765 & 408 & n.s. & n.s. & n.s. \\
\hline $\begin{array}{c}\text { Oleic Acid } \\
\text { (nmol/2hr } \\
\text { per g tissue) }\end{array}$ & 1732 & 1620 & 1155 & 2197 & 226 & n.s. & $P<0.01$ & n.s. \\
\hline $\begin{array}{c}\text { Glucose } \\
\text { (nmol/2hr } \\
\text { per g tissue) }\end{array}$ & 746 & 845 & 652 & 939 & 121 & n.s. & n.s. & n.s. \\
\hline $\begin{array}{l}\text { Glutamine } \\
\text { (nmol/2hr } \\
\text { per g tissue) }\end{array}$ & 162 & 234 & 199 & 197 & 29.8 & n.s. & n.s. & n.s. \\
\hline
\end{tabular}

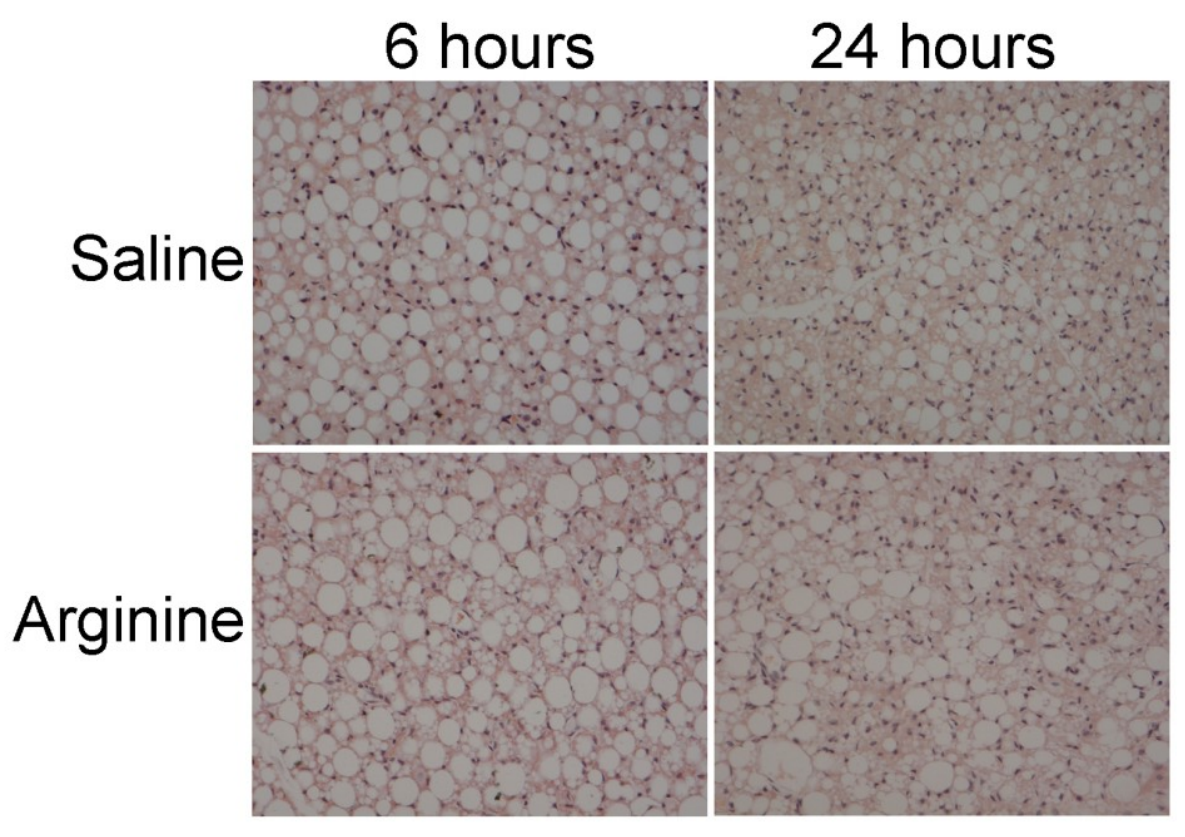

Figure 3.2. Gross morphology of BAT from lambs born to saline and arginine treated mothers. There is a reduction in the number and/or size of the lipid droplets in BAT collected at 24 hours of age as compared to BAT collected at 6 hours of age. Width of field is $420 \mu \mathrm{m}$. 


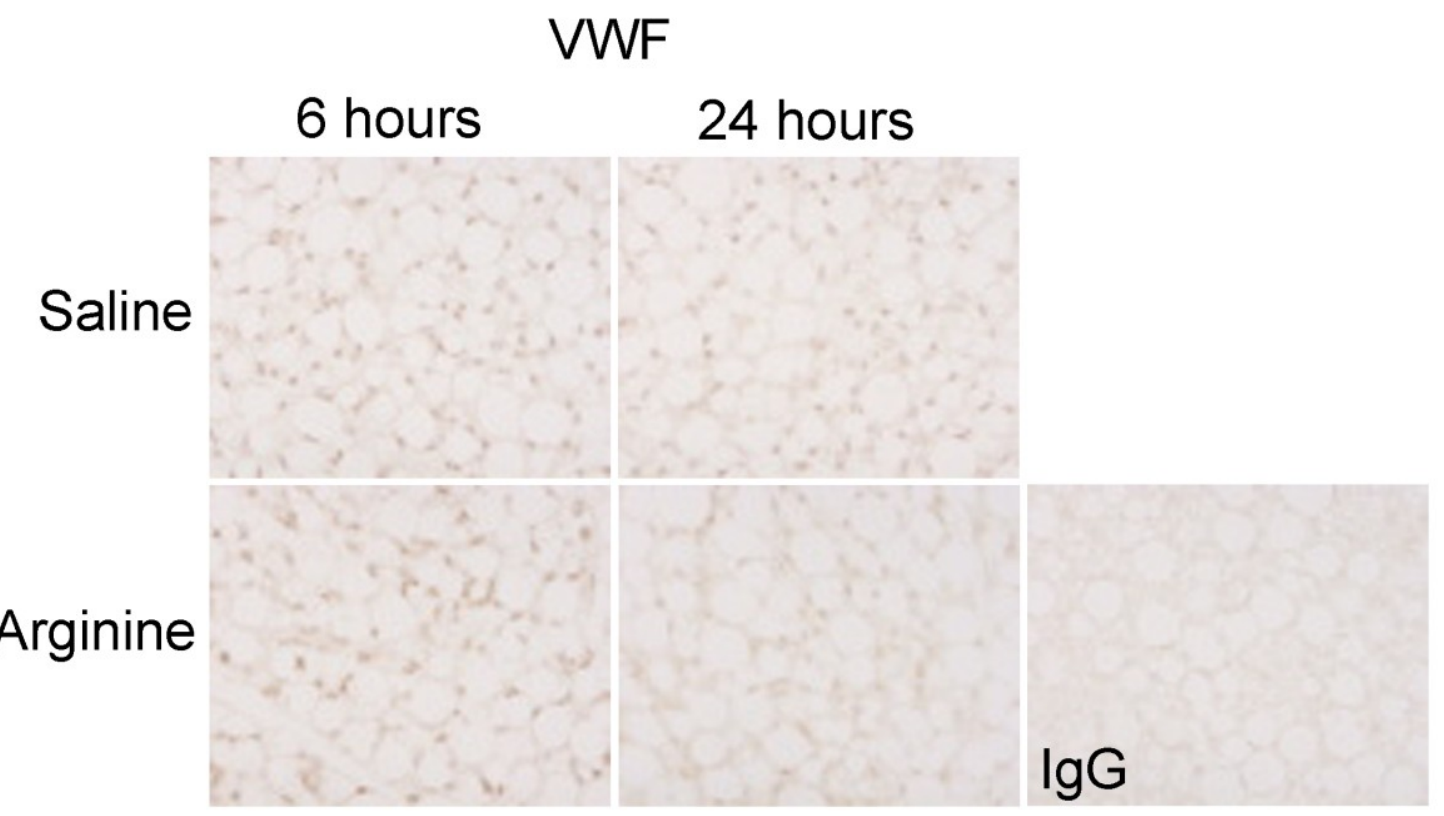

Figure 3.3. Immunohistochemical localization of VWF in sections of BAT. Tissues are from lambs of arginine and saline treated ewes necropsied at 6 and 24 hours of age using a rabbit $\operatorname{IgG}$ as a negative control. Width of field is $210 \mu \mathrm{m}$.

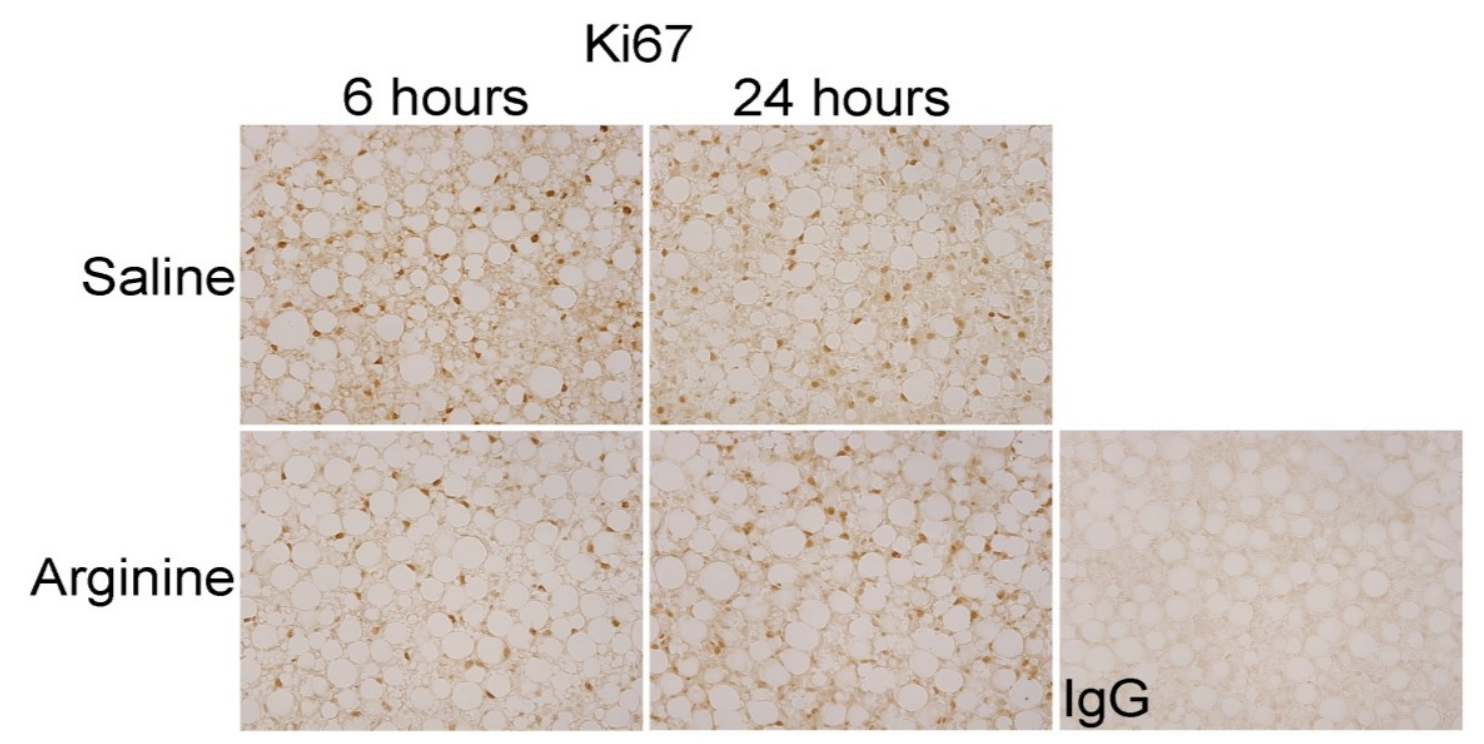

Figure 3.4. Immunohistochemical localization of Ki67 in sections of BAT. Tissues are from lambs of arginine and saline treated ewes necropsied at 6 and 24 hours of age using a mouse IgG as a negative control. Width of field is $210 \mu \mathrm{m}$. 


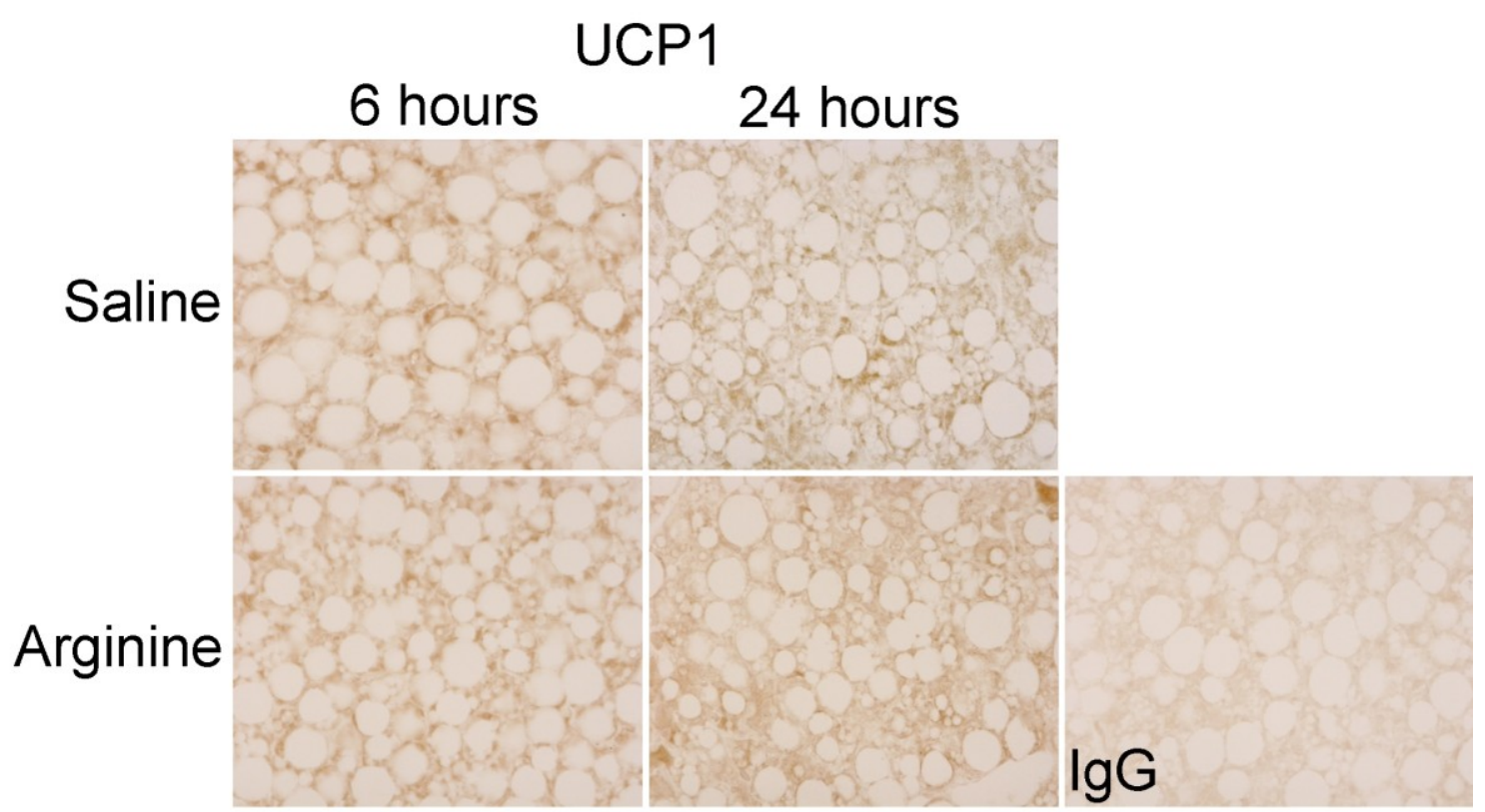

Figure 3.5. Immunohistochemical localization of UCP1 in sections of BAT. Tissues are from lambs of arginine and saline treated ewes necropsied at 6 and 24 hours of age using a rabbit IgG as a negative control. Width of field is $210 \mu \mathrm{m}$.

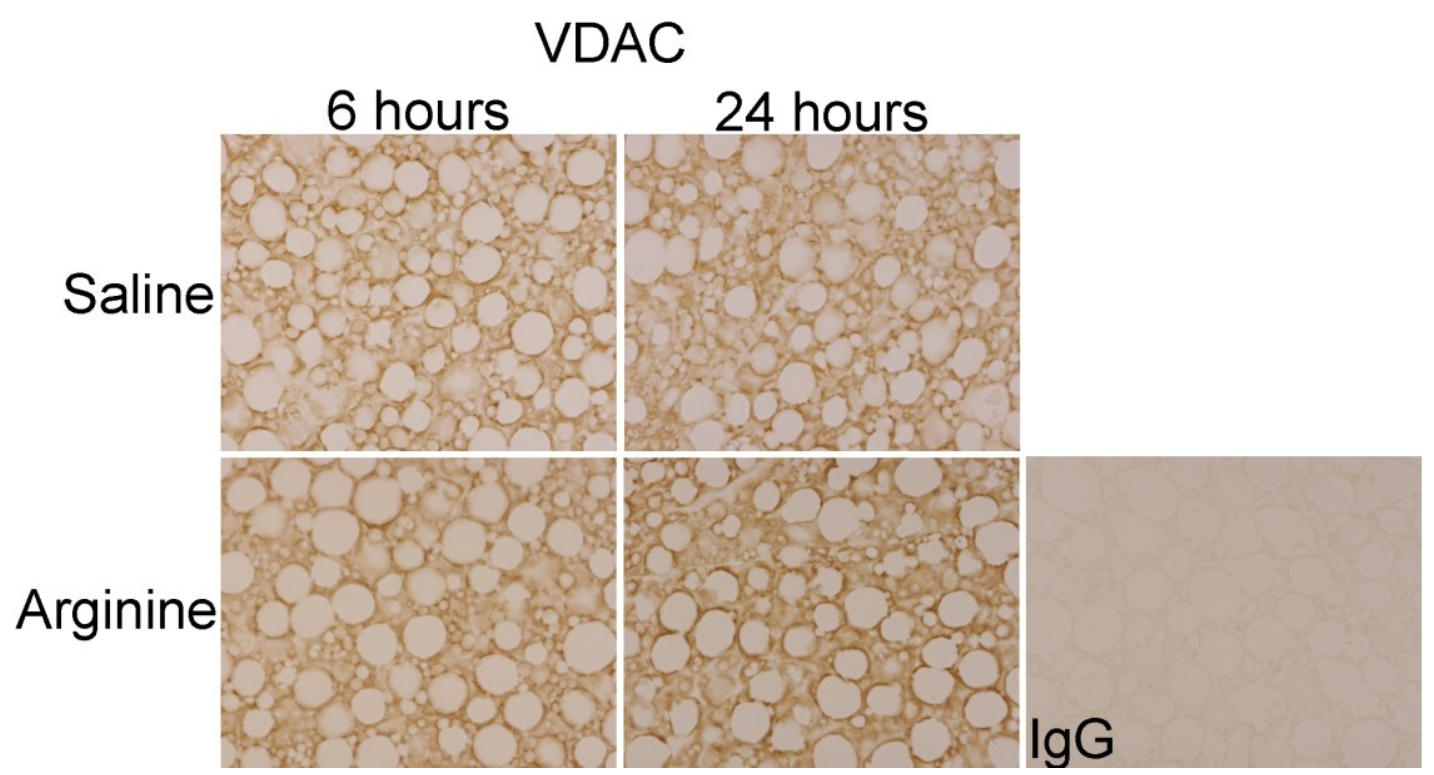

Figure 3.6. Immunohistochemical localization of VDAC in sections of BAT. Tissues are from lambs of arginine and saline treated ewes necropsied at 6 and 24 hours of age using a rabbit IgG as a negative control. Width of field is $210 \mu \mathrm{m}$. 


\section{Real-time PCR}

The effects of maternal L-arginine supplementation on mRNA expression for candidate genes hypothesized to be involved in BAT growth and development, mitochondrial biogenesis, and arginine function were determined using quantitative Real-time PCR (Table 3.4). Arginine treatment had no effect on UCP1, TEK, PPARG1CA, NRF1, NRF2, FRAP1, PPARG, ADRB3, ARG2, RPS6K1, EIF4EBP1, COX7B, NOS3, or ODC1. However, TEK, PPARGC1A, NRF1, NRF2, PPARG, ADRB3, ARG2, RPS6K1, EIF4EBP1, LPL, and ODC1 steady-state mRNA levels were increased $(\mathrm{P}<0.05)$ at 24 versus 6 hours of age. Of these genes, only EIF4EBP1 tended to be upregulated $(\mathrm{P}=0.057)$ in $\mathrm{BAT}$ in response to maternal arginine administration.

\section{DISCUSSION}

In a recent study we found that maternal supplementation with L-arginine from days $100-125$ of gestation (term=147) resulted in a $62 \%$ increase in fetal BAT mass on day 125 of gestation (Satterfield et al. 2009). Based on these exciting findings, we conducted the present study to determine if increased fetal BAT mass achieved by maternal arginine supplementation could improve neonatal thermogenesis in response to acute cold challenge. 
TABLE 3.4. Effect of age at challenge time and treatment on BAT gene mRNA expression by Real-time PCR presented as fold difference.

\begin{tabular}{|c|c|c|c|c|c|c|c|c|}
\hline \multirow[b]{2}{*}{ Gene } & \multicolumn{2}{|c|}{6 Hours } & \multicolumn{2}{|c|}{24 Hours } & \multirow[b]{2}{*}{ SE } & \multirow[b]{2}{*}{ Trt } & \multirow[b]{2}{*}{ Age } & \multirow[b]{2}{*}{ Trt X Age } \\
\hline & $\begin{array}{l}\text { Saline } \\
(n=14)\end{array}$ & $\begin{array}{c}\text { Arginine } \\
(n=18)\end{array}$ & $\begin{array}{c}\text { Saline } \\
(n=6)\end{array}$ & $\begin{array}{c}\text { Arginine } \\
(n=4)\end{array}$ & & & & \\
\hline UCP1 & 1 & 0.979 & 0.989 & 1.254 & 0.06 & n.s. & n.s. & n.s. \\
\hline PPARG1CA & 1 & 0.843 & 1.419 & 1.653 & 0.092 & n.s. & $P<0.01$ & n.s. \\
\hline TEK & 1 & 0.951 & 1.277 & 1.362 & 0.072 & n.s. & $P<0.05$ & n.s. \\
\hline NRF1 & 1 & 1.06 & 1.355 & 1.581 & 0.055 & n.s. & $P<0.01$ & n.s. \\
\hline NRF2 & 1 & 1.16 & 1.218 & 1.389 & 0.043 & n.s. & $P<0.05$ & n.s. \\
\hline FRAP1 & 1 & 0.854 & 1.075 & 1.282 & 0.078 & n.s. & n.s. & n.s. \\
\hline RPS6K1 & 1 & 1.008 & 1.821 & 1.792 & 0.057 & n.s. & $P<0.0001$ & n.s. \\
\hline EIF4EBP1 & 1 & 1.499 & 2.19 & 3.302 & 0.157 & n.s. & $P<0.01$ & n.s. \\
\hline ARG2 & 1 & 1.174 & 1.561 & 1.829 & 0.073 & n.s. & $P<0.01$ & n.s. \\
\hline ODC1 & 1 & 1.211 & 2.003 & 2.419 & 0.07 & n.s. & $P<0.0001$ & n.s. \\
\hline NOS3 & 1 & 1.441 & 0.978 & 1.125 & 0.072 & n.s. & n.s. & n.s. \\
\hline $\mathrm{LPL}$ & 1 & 1.478 & 2.46 & 3.14 & 0.162 & n.s. & $P<0.01$ & n.s. \\
\hline COX7B & 1 & 1.019 & 1.287 & 1.139 & 0.125 & n.s. & n.s. & n.s. \\
\hline PPARG & 1 & 0.893 & 1.405 & 1.674 & 0.071 & n.s. & $P<0.01$ & n.s. \\
\hline ADRB3 & 1 & 1.468 & 1.619 & 1.902 & 0.092 & n.s. & $P<0.05$ & n.s. \\
\hline
\end{tabular}

SE represents the overall standard error. 
Results of the present study indicate that maternal arginine supplementation from days 75-125 of gestation increased neonatal rectal temperature over the course of two, two-hour cold challenges on the first day of life. Interestingly, results also indicate that at necropsy, following each cold challenge BAT mass was not different between lambs born from mothers receiving either saline or arginine. Further, BAT composition, metabolism, histology, and mRNA expression of candidate genes were not different between lambs from arginine and saline-treated ewes despite the increased thermogenic capacity.

Insufficient ability to maintain homeothermy after birth is the leading cause of non-predator related peri-natal mortality in sheep (Simpson 1995). As BAT is responsible for $50 \%$ of the heat generated in the newborn lamb it is not surprising that previous studies have attempted to increase BAT accretion (Symonds and Lomax 1992). Despite these efforts, to date, studies have in large part failed to identify dietary strategies to improve fetal BAT growth and/or neonatal thermogenesis. Lammoglia et al. (1999b) found that supplementing high fat to beef heifers during the latter stages of gestation resulted in higher circulating glucose concentrations and an increased ability to sustain rectal temperature following cold challenge. However, calves born to high fatfed mothers had a considerably lower initial rectal temperature, therefore at the end of the 140-minute cold challenge rectal temperatures between the low fat and high fat fed calves were similar. A longer cold-challenge would be needed to determine if calves from high-fat fed mothers exhibit improved survival. In addition, feeding a high fat diet during fetal development may have long-lasting negative consequences on growth and 
performance. The observation that calves had higher circulating concentrations of glucose at all time points in the study may indicate that glucose tolerance and insulin sensitivity is altered in these animals. Impaired glucose tolerance and insulin sensitivity may contribute to increased adiposity and decreased efficiency of growth, as observed in other mammalian species (Cerf et al. 2006; Cerf et al. 2005; Ford et al. 2009; Long et al. 2010; Shiell et al. 2000; Srinivasan et al. 2006; Yan et al. 2011; Zhang et al. 2011). In the present study, neonatal rectal temperature was not only greater during the course of the two 2-hour cold challenges in lambs born from arginine-treated ewes, but was also greater at time zero of both challenges. These observations suggest that non-shivering thermogenesis is an important mediator of homeothermy even when ambient temperatures are rather warm. The fact that rectal temperature was elevated by a half degree centigrade in response to maternal arginine supplementation is significant. As the animal transitions from the pre-challenge environment $\left(\sim 20^{\circ} \mathrm{C}\right)$ to the challenge environment $\left(0^{\circ} \mathrm{C}\right)$, the natural physiological response results in an increase in rectal temperature by slightly less than a full degree centigrade. Therefore, simply by supplying the mother with supplemental arginine during gestation we can improve the natural physiological response to cold by $50 \%$.

The observation that fetal BAT mass was not increased in lambs born to arginine-treated ewes following the cold challenge was not in whole, unexpected. Given that rectal temperatures were not only greater during the cold challenge, but also prior to the start of the cold challenge in lambs from arginine-treated ewes, indicate that nonshivering thermogenesis was active during this time. This process requires substantial 
substrate for the generation of heat, therefore it would be expected that BAT mass would diminish more rapidly in lambs that were more thermogenically active. This train of thought is also supported by the observation that BAT mass was reduced by some $30 \%$ between animals collected at the end of the second cold challenge as compared to the end of the first challenge. A similar, but slightly lower, reduction in BAT mass following a second cold challenge was observed by Chen et al. (2007) using a similar study design. Interestingly, results of the present study indicate that even at 6 hours of age, peri-renal BAT mass is not different between lambs from arginine- and salinetreated ewes, yet at 22 hours of age and continuing throughout the second coldchallenge, lambs from arginine-treated ewes were warmer than lambs from saline-treated ewes. Given, these results one must question whether maternal arginine supplementation not only increases fetal BAT mass (at least at day 125 of gestation), but may also/alternatively enhance thermogenic capacity per unit tissue. Indeed, it is possible that BAT mass was not different between lambs from saline and argininetreated ewes at the time of birth, which could not be determined as this study did not collect BAT at the time of birth. It is possible that the prior observation that maternal arginine supplementation increased BAT mass at day 125 of gestation simply represented an acceleration of BAT growth to that point and that fetal BAT growth in saline-treated ewes caught-up by parturition.

We next wanted to determine potential mechanisms by which maternal arginine supplementation could increase BAT mass and/or function. Gross histological and compositional analyses suggested that maternal arginine supplementation did not alter 
the gross morphology or the cellular composition of the tissue, including the quantities of intracellular lipid, protein, and mitochondrial protein, as well as the vascular network supplying BAT with essential substrate and removing its product, heat. Given that maternal arginine supplementation did not alter gross composition of fetal BAT we proceeded to determine changes in mRNA expression of candidate genes known to be involved in arginine metabolism, BAT function, and/or mitochondrial biogenesis. Interestingly, maternal arginine treatment did not alter mRNA expression of any of the candidate genes with the exception of EIF4EBP1, which only tended to be increased in response to maternal arginine supplementation. Despite this lack of findings in response to maternal arginine supplementation, a number of genes were altered by age and/or repeated exposure to cold. Results of the present study indicate that total mitochondrial protein was greater in BAT of lambs at 24 hours of age than at 6 hours of age. This was supported by the observation that several genes involved in mitochondrial biogenesis, including NRF1, NRF2, RPS6K1, EIF4EBP1, and PPARGC1A were upregulated at 24 versus 6 hours of age (D'Souza et al. 2007; Nisoli et al. 2004). Interestingly, FRAP1 (also known as mammalian target of rapamycin, MTOR), was not affected by age, however, its downstream targets, RPS6K1 and EIF4EBP1 were increased at 24 hours of age. FRAPl has been shown to promote mitochondrial biogenesis during $\mathrm{T}$ cell activation (D'Souza et al. 2007)

Also of interest was the observation that $U C P 1$ mRNA and protein expression was not affected by arginine treatment or age. In contrast, Chen et al. (2007) found that UCP1 mRNA expression declined by nearly 4-fold between 6 and 24 hours of age 
following similar cold challenges. Further confounding these findings was the observation that UCP1 mRNA levels increased from 4 to 24 hours of age and then declined to undetectable levels 30 days after birth (Mostyn et al. 2003). The seemingly contradictory results from these three studies suggest further investigation is warranted.

In summary, results of the present study indicate that maternal arginine supplementation during the latter half of gestation increases neonatal thermogenesis in response to acute cold exposure. Translation of these exciting results into nutritional management strategies for ruminants has significant potential to reduce neonatal mortality and morbidity. The observation that maternal arginine treatment did not alter BAT composition or expression of key genes involved in BAT function was surprising. Future studies are needed to determine at what stage during fetal development arginine acts to promote BAT growth, including if arginine stimulates proliferation or recruitment of pre-brown adipocyte stem cells. Future studies are also necessary to determine if maternal arginine supplementation alters BAT function via novel regulatory pathways.

\section{MATERIALS AND METHODS}

\section{Experimental Design}

Multiparous Suffolk ewes ( $\mathrm{n}=31)$ gestating twins and singletons were maintained and cared for at the Texas A\&M University Sheep Center. Twin pregnancies were chosen in addition to singletons in order to provide two lambs from each ewe for determining thermogenic capacity at different time points of 6 hours and 24 hours while reducing variation due to maternal effects. Pregnancies were determined on day 35 of gestation by ultrasonography. The ewes were held in separate pens and fed to meet 
$100 \%$ of their National Research Council requirements throughout gestation. Each group received intravenous infusion of either arginine ( $27 \mathrm{mg} / \mathrm{kg}$ bodyweight; $\mathrm{n}=17)$ or saline $(n=14)$ three times daily from day 75 to day 125 of gestation (term=147) (Figure 3.7).

\section{Maternal Administration of Arginine}

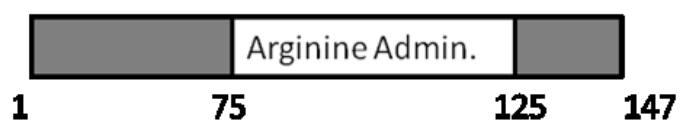

\section{Treatment Groups}

1. $100 \% \mathrm{NRC}+$ Sallne $(n=17)$

2. $100 \%$ NRC + Arginlne $(n=20)$

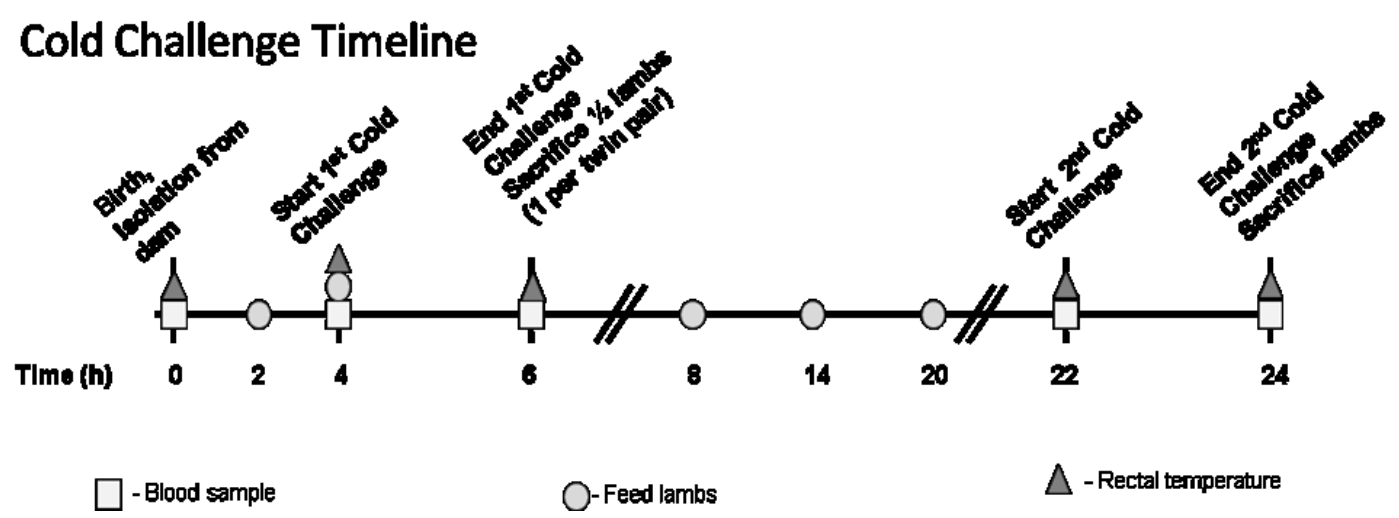

Figure 3.7. Experimental design. Ewes were fed $100 \%$ of NRC-recommended nutrition throughout gestation. Beginning at Day 75 of gestation, ewes received intravenous injections of L-arginine or saline until Day 125. At birth, lambs were isolated from their dams and placed in a thermoneutral zone of $25^{\circ} \mathrm{C}$ until 4 hours of age. They were then placed in a cold chamber of $0^{\circ} \mathrm{C}$ for 2 hours with rectal temperatures recorded every 15 minutes. Following the challenge, all singleton lambs and one lamb from each twin pair was sacrificed and BAT was collected and weighed. Blood was drawn from the lambs at 0, 4, 6, 22, and 24 hours of age. Experimental design adapted from Chen et al. 2007. 


\section{Blood Sampling}

Maternal blood samples $(3 \mathrm{ml})$ were collected immediately following parturition and blood samples $(3 \mathrm{ml})$ from the lambs were collected at birth, 4 hours of age, and 6 hours of age for all lambs and at 22 hours and 24 hours of age for remaining twin lambs that were not sacrificed at 6 hours of age. The samples were analyzed for glucose, fatty acids, and norepinephrine using enzymatic assays (Fu et al. 2005; Wu and Meininger 2008).

\section{Determining Neonatal Response to Acute Cold Stress and Tissue Collection}

Directly after birth, the newborn lambs were removed from the dam and placed into a thermoneutral zone of approximately $25^{\circ} \mathrm{C}$. The newborns were fed warmed pooled colostrum (30ml/ $\mathrm{kg}$ body weight) at 2 hours of age and then $60 \mathrm{ml}$ of warmed saline at 4 hours of age. The lambs were placed into a cold chamber at 4 hours of age and remained in the chamber for 2 hours. At 15 minutes intervals, rectal temperatures were obtained. Following the cold challenge, all singleton lambs and one lamb from the twin pair were sacrificed with an overdose of sodium pentobarbital (Chen et al. 2007). Fetal peri-renal BAT was collected and weighed (Chen et al. 2007). The remaining twin lamb was placed back into the warm chamber until 22 hours of age. At 8, 14, and 20 hours of age, the lambs were fed warmed pooled colostrum $(30 \mathrm{ml} / \mathrm{kg}$ body weight $)$. At 22 hours of age, the remaining lamb was fed $60 \mathrm{ml}$ of warmed saline and placed back into the cold chamber for a second challenge for a 2 hour period. After the challenge, the lamb was sacrificed and BAT was collected and weighed. Sections of BAT were snap-frozen in liquid nitrogen and stored at $-80^{\circ} \mathrm{C}$ and fresh samples will immediately be 
used for mitochondrial extraction. A small portion was collected and stored at $-20^{\circ} \mathrm{C}$ to later be fixed using standard glutaraldehyde fixation techniques for histological studies, as previously described (Smith and Prior 1984).

\section{Biochemical Analysis of Lamb Plasma}

Glucose was measured using an enzymatic method previously described using a spectrophotomic method involving hexokinase and glucose-6-phosphate dehydrogenase (Wu et al. 1995). Free fatty acids (NEFA) were measured using a commercial assay kit (catalog no. 994-75409; Wako Chemicals) according to the manufacturer's recommendations (Jobgen et al. 2009). Norepinephrine levels were measured using a commercial assay kit (17-NORHU-E0; Alpco) according to the manufacturer's recommendations.

\section{Biochemical Analysis of Lamb BAT}

Oxidation of amino acids, glucose, and fatty acids were analyzed with minced BAT tissue as previously described in (Fu et al. 2005; Wu et al. 1995). At time of necropsy, samples were placed into Dulbecco's Modified Eagle Medium (DMEM) (Invitrogen, Cat\# D6429-1L) and immediately analyzed.

\section{BAT Protein Extraction}

Protein extraction of the fetal lamb BAT that was previously snap frozen in liquid nitrogen was carried out using a lysis buffer composed of $60 \mathrm{mM}$ Tris- $\mathrm{HCl} \mathrm{pH} 7.0$, $1 \mathrm{mM}$ Sodium Orthovanadate $\left(\mathrm{Na}_{3} \mathrm{VO}_{4}\right), 10 \%$ Glycerol, 2\% Sodium dodecyl sulfate (SDS), Complete EDTA-free Protease Inhibitor Cocktail Tablet (Roche, Cat\# 04693 132 001). Approximately $100 \mathrm{mg}$ of fetal lamb BAT was weighed out and placed in a 
glass Pyrex tissue homogenizer with $2 \mathrm{ml}$ of lysis buffer. Tissues were kept on ice and ground for 30 seconds two times. Samples were then transferred to $1.5 \mathrm{ml}$ tubes and centrifuged at max speed for 15 minutes at $4{ }^{\circ} \mathrm{C}$. The supernatant was aliquoted and stored at $-20^{\circ} \mathrm{C}$. Total protein concentration was determined by a DC Protein Assay (Bio-Rad, Cat\# 500-0116) as recommended by the supplier with bovine serum albumin (BSA) as the standard.

\section{Total Lipid Concentration Determination in BAT}

Snap frozen samples of BAT were used to determine total lipid concentration using a modified version of the Folch method. Samples of 0.5 grams were placed into a $50 \mathrm{~mL}$ screw cap tube and each sample was performed in duplicate. Once the sample was placed into a $50 \mathrm{ml}$ glass vial, $10 \mathrm{ml}$ of 2:1 Chloroform: Methanol (v/v) was added to the tube. The sample was then homogenized in the vial and then stored overnight. On day 2 , the homogenized sample was filtered into a new $50 \mathrm{~mL}$ screw cap tube containing $10 \mathrm{ml}$ fresh 2:1 Chloroform: Methanol (v/v) using the glass filter apparatus and glass fiber filters. The tube was then rinsed with $5 \mathrm{ml} \mathrm{2:1} \mathrm{Chloroform:} \mathrm{Methanol} \mathrm{(v/v).} \mathrm{Once}$ the sample was thoroughly vortexed, $8 \mathrm{ml}$ of $\mathrm{KCl}(0.74 \%)$ were added and vortexed again and allowed to incubate at $4{ }^{\circ} \mathrm{C}$ for $1-2$ hours. After incubation, 2 layers are present in the vial and the top layer was removed using a suction device. The remaining bottom layer of the sample was placed into a new $20 \mathrm{ml}$ glass vial that had previously been dried in an incubator and weighed (Vial 1). The vial was then placed on a nitrogen evaporator until the remaining liquid has evaporated. The vial (Vial 2) was then weighed and the following formula was used to determine total lipid concentration: 


$$
\frac{(\text { Weight of Vial } 2(\mathrm{~g})-\text { Weight of Vial } 1(\mathrm{~g})) \times 1.26}{\text { Weight of the sample (g) }} \times 100
$$

\section{Isolation of Mitochondria and Total Mitochondrial Protein Determination}

Isolation of mitochondria for total mitochondrial protein determination utilized fresh BAT by differential centrifugation as described by Cannon and Lindberg (Cannon and Lindberg 1979). These samples were stored at $-80 \mathrm{C}$ for later determination of total mitochondrial protein concentration. The total mitochondrial protein assay was performed in the same manner as the total protein concentration from BAT was determined by a $D C$ Protein Assay (Bio-Rad, Cat\# 500-0116) as recommended by the supplier with bovine serum albumin (BSA) as the standard.

\section{Histological Analysis}

For histological analysis of BAT, embedded tissues were sectioned $(5 \mu \mathrm{m})$ were cut on a microtome and affixed to glass slides (Smith and Prior 1984). They were then deparaffinized and hydrated prior to staining with Hematoxylin and Eosin Stain for gross histological analysis as previously described (Gray et al. 2000). Representative photomicrographs of BAT sections were captured using a Nikon Eclipse 1000 photomicroscope (Nikon Instruments Inc., Lewisville, TX) fitted with a Nikon DXM1200 digital camera and assembled using Adobe Photoshop 7.0 (Adobe Systems, Seattle, WA).

\section{Immunohistochemistry}

BAT was fixed in $4 \%$ paraformaldehyde (vol/vol), followed through washing in $70 \%$ ethanol, and tissues were processed, embedded in paraffin, and sectioned. BAT 
sections were made from the paraffin-embedded tissue and were cut at $5 \mu \mathrm{m}$ and mounted on slides, deparaffinized, and rehydrated in a graded alcohol series. The sections were then subjected to antigen retrieval using the boiling citrate buffer method as described previously described (Dunlap et al. 2011). Immunohistochemical localization of immunoreactive VWF, VDAC1, UCP1, and Ki-67 proteins was detected in BAT tissue cross-section using specified antibodies and either a rabbit/mouse immunoglobulin G (IgG) Kit (Biomeda, Foster City, CA). VDAC1, VWF, and UCP1 proteins were detected using a primary rabbit monoclonal antibody at final concentrations of 1:500, 1:500, 1:1000 respectively and a Vectastain ABC anti-rabbit kit (Vector Laboratories, Inc., Burlingame, CA). Ki-67 protein was detected using mouse monoclonal antibody against at a final concentration of 1:500 and a Vectastain $\mathrm{ABC}$ anti-mouse kit (Vector Laboratories, Inc., Burlingame, CA). Immunoreactive protein was visualized using diaminobenzidine tetrahydrochloride (Sigma) as the chromagen and the sections were coverslipped using Permount.

\section{RNA Isolation and Real-Time PCR Analysis}

Total cellular RNA was isolated from frozen BAT using Trizol reagent (GibcoBRL, Bethesda, MD) according to the manufacturer's instructions. The quantity and the quality of tRNA were determined by spectrometry and by denaturing agarose gel electrophoresis, respectively. Total RNA samples were digested with RNase-free DNase I and were cleaned up using the RNeasy MinElute Cleanup Kit (Qiagen, Valencia, CA). Synthesis of cDNA from total cellular RNA $(2 \mu \mathrm{g})$ using random primers (Invitrogen, 
TABLE 3.5. Primer sequences for Real-Time quantitative PCR

\begin{tabular}{|c|c|c|c|c|}
\hline $\begin{array}{c}\text { Entrez } \\
\text { Gene } \\
\text { Symbol } \\
\end{array}$ & Gene Name & $\begin{array}{c}\text { Accession } \\
\text { Number }\end{array}$ & Forward Primer & Reverse Primer \\
\hline$A D R B 3$ & Adrenergic beta-3 receptor & NM_001159757.1 & CCGCTCGACGGGTAGGTA & GACCAGCGGAGATACAGAAAGC \\
\hline FRAP1 & $\begin{array}{c}\text { FK506 binding protein 12- } \\
\text { rapamycin associated } \\
\text { protein } 1\end{array}$ & XM_417614.2 & GAGACCGTGGACCGTCTGA & GTGTGCGTACAATCGGATGAA \\
\hline$P P A R G$ & $\begin{array}{l}\text { Peroxisome proliferator- } \\
\text { activated receptor gamma }\end{array}$ & NM_001100921.1 & GCGTGCACGAGATCATTTACA & TGAGGACCCCATCCTTATTCAT \\
\hline$T U B A$ & Alpha tubulin & AF251146 & GGTCTTCAAGGCTTCTTGGT & CATAATCGACAGAGAGGCGT \\
\hline$A R G 2$ & Arginase type II & DQ152925.1 & GCCAATCCATCTGAGTTTCGAT & ATACATGCCTTCTCGATAGGTCAGT \\
\hline$C O X 7 B$ & $\begin{array}{l}\text { Cytochrome c oxidase } \\
\text { subunit VIIb }\end{array}$ & EF693802 & AGCTGACCCACGCCGAA & TCATCTCCGCAAAGGTCTCAT \\
\hline EIF $4 E B P 1$ & $\begin{array}{c}\text { Eukaryotic translation } \\
\text { initiation factor } 4 \mathrm{E} \text { binding } \\
\text { protein } 1\end{array}$ & NM_004095 & GGCGGCACGTCTTTCA & TCAGGAATTTCCGGTCATAGATG \\
\hline$L P L$ & Lipoprotein lipase & AF228667 & AACTAGTCAAGAGTGTGAGTGAAC & ATGTCAATCACAGCATTCATTCTACT \\
\hline NOS3 & Nitric oxide synthase 3 & DQ015701 & TTTCAGGCACAGTCCTCTCA & AGGCGCACCAGGATGGT \\
\hline NRF1 & Nuclear respiratory factor-1 & NM_001098002 & CAGCAAGCCATTGTCCTTTGTA & AAGGAGCTGCACCGAACACT \\
\hline$N R F 2$ & Nuclear respiratory factor-2 & AY369137.1 & GATGTTAATGCAAAAGACATGTTGAA & TTCCACCACCTCTTGATGATT \\
\hline PPARGC1A & $\begin{array}{c}\text { Peroxisome proliferator- } \\
\text { activated receptor gamma, } \\
\text { coactivator } 1 \text { alpha }\end{array}$ & AY345941.1 & GAACCGGAACAGCAGCAGAG & TTGCGTCTGCGATTGTGTG \\
\hline ODC1 & Ornithine decarboxylase 1 & NM_174130.2 & GCTGAAGAGCAGCTCCATGTT & AAGGCGGCTCGATCATCA \\
\hline RPS6KA1 & Ribosomal protein S6 kinase & NM_001083722.1 & GGCAGCTACCTACTCAGCACTCA & TAGACGACTCGATGGGCTTCA \\
\hline TEK & Tyrosine kinase & NM_173964.2 & TCCTGGACTTCCTGCGAAAG & GTGTGGAGGCAGTGCTGTTG` \\
\hline$U C P 1$ & $\begin{array}{l}\text { Mitochondrial uncoupling } \\
\text { protein }\end{array}$ & XM616977 & CAGTGAAACTCTACATGTGGCTGC & TGGTGAAGAACTCCTGGACAGTATC \\
\hline
\end{tabular}


Carlsbad, CA), oligo-dT primers, and SuperScript II Reverse Transcriptase (Invitrogen) as described previously (Stewart et al. 2000). PCR cycle parameters were $95{ }^{\circ} \mathrm{C}$ for 5 minutes, $95{ }^{\circ} \mathrm{C}$ for 30 seconds, $58.1^{\circ} \mathrm{C}$ for 30 seconds, $72^{\circ} \mathrm{C}$ for 30 seconds, and $72^{\circ} \mathrm{C}$ for 7 minutes for 29 cycles and held at $4{ }^{\circ} \mathrm{C}$. Primers were designed for all genes selected for qPCR, based on sequences from the database by Primer Express (Applied Biosystems). Real-time PCR was carried out in $10 \mu \mathrm{l}$ reactions containing $9 \mu \mathrm{l}$ of $2 \mathrm{X}$ SYBR Green PCR Master Mix (Applied Biosystem). RT-PCR was used to determine the presence of the genes $A R G 2, C O X, E I F 4 E B P 1, F R A P 1, L P L, N O S 3, N R F 1, N R F 2$, PRDM16, PPARGC1A, ODC1, RPS6KA1, TEK, UCP1, ADRB3, and PPARG (Table 3.5).

\section{Statistical Analysis}

Data was analyzed statistically by ANOVA, using the General Linear Model procedures of the Statistical Analysis System (SAS, 2002). Differences between means were determined using the Student-Newman-Keuls multiple comparison test. Data obtained from the rectal temperatures will analyzed as repeated measures data using SAS procedures. Probability values $\leq 0.05$ were taken to indicate statistical significance. 


\section{CHAPTER IV}

\section{SUMMARY AND DIRECTION OF FUTURE RESEARCH}

To our knowledge, this study is the first to report that maternal L-arginine administration during mid to late-gestation enhances neonatal thermogenesis in the lamb. While L-arginine supplementation has been shown to increase thermogenic responses in the rodent, its role in regulating neonatal thermogenesis in sheep had not been investigated. This novel finding has great potential for improving profitability of sheep producers as $40 \%$ of non-predator related lamb deaths are attributed to cold stress and cold related losses. For this study, we infused L-arginine intravenously three times daily to ewes from Day 75 to Day 125 of gestation. As this is not a practical method of supplemental administration, further studies are needed to examine the effects of administering dietary L-arginine in extensive range conditions in order to determine 1) the efficacy of administering rumen-protected arginine to increase neonatal thermogenesis, and 2) the effect of maternal arginine supplementation on neonatal survival and postnatal growth in a large-scale production setting. 


\section{REFERENCES}

Affourtit C, Crichton P, Parker N, Brand M. 2007. Novel uncoupling proteins. Novartis Found Symp 287:70-80.

Afzelius B. 1970. Brown adipose tissue: its anatomy, histology and cytology. In: Lindberg O, editor. Brown Adipose Tissue. New York: American Elsevier. pp 131 .

Alderton W, Cooper C, Knowles R. 2001. Nitric oxide synthases: structure, function and inhibition. Biochemical J 357:593-615.

Alexander G. 1978. Quantitative development of adipose tissue in foetal sheep. Aust J Biol Sci 35(5):489-503.

Alexander G. 1981. Development of brown-fat in the sheep fetus: preparation for neonatal thermogenesis. Proc Austr Physiol Pharmacol Soc 12:31-35.

Alexander G. 1984. Constraints to lamb survival: a review. In: Lindsay D, Pearce D, editors. Reproduction in Sheep. Canberra: Australian Wool Coorporation. pp 199-208.

Azzam S, Kinder J, Nielson M, Werth L, Gregory K, Cundiff I, Kock R. 1993. Environmental effects on neonatal mortality of beef calves. J Anim Sci 71:282290.

Barak Y, Nelson MC, Ong ES, Jones YZ, Ruiz-Lozano P, Chien KR, Koder A, Evans RM. 1999. PPAR[gamma] is required for placental, cardiac, and adipose tissue development. Mol Cell 4(4):585-595.

Beevers CS, Li F, Liu L, Huang S. 2006. Curcumin inhibits the mammalian target of rapamycin-mediated signaling pathways in cancer cells. Int J Cancer 119(4):757764.

Berg F, Gustafson U, Anderson L. 2006. The uncoupling protein 1 gene (UCP1) is disrupted in the pig lineage: a genetic explanation for poor thermoregulation in piglets. PLoS Genet 2(8):e129.

Brown GC. 2007. Nitric oxide and mitochondria. Front Biosci 12:1024-1033.

Budge H, Bispham J, Dandrea J, Evans E, Heasman L, Ingleton PM, Sullivan C, Wilson V, Stephenson T, Symonds ME. 2000. Effect of maternal nutrition on brown adipose tissue and its prolactin receptor status in the fetal lamb. Ped Res 47(6):781-786. 
Bukowiecki L, Collet A, Follea N. 1982. Brown adipose tissue hyperplasia: a fundamental mechanism of adaptation to cold and hyperphagia. Am J Physiol(242):353-359.

Cannon B, Connoley E, Obregon M, Nedergaard J. 1988. Perinatal activation of brown adipose tissue. In: Kunzel W, Jesen A, editors. The Endocrine Control of the Fetus. Berlin: Springer Verlag. pp 306-320.

Cannon B, Lindberg O. 1979. Mitochondria from brown adipose tissue: isolation and properties. Methods Enzymol 55:65-78.

Cannon B, Nedergaard J. 2004. Brown adipose tissue: function and physiological significance. Physiol Rev 84(1):277-359.

Casteilla L, Champigny O, Bouillaud F, Robelin J, Ricquier D. 1989. Sequential changes in the expression of mitochondrial protein mRNA during the development of brown adipose tissue in bovine and ovine species. Biochem J 257:665-671.

Cerf ME, Muller C, Du Toit D, Louw J, Wolfe Coote S. 2006. Hyperglycaemia and reduced glucokinase expression in weanling offspring from dams maintained on a high-fat diet. Br J Nutr 95(2):391-396.

Cerf ME, Williams K, Nkomo XI, Muller CJ, Du Toit DF, Louw J, Wolfe Coote SA. 2005. Islet cell response in the neonatal rat after exposure to a high-fat diet during pregnancy. Am J Physiol Regul Integr Comp Physiol 288(5):R1122-1128.

Chen C, Carstens G, Gilbert C, Theis C, Archibeque S, Kurz M, Slay L, Smith S. 2007. Dietary supplementation of high levels of saturated and monounsaturated fatty acids to ewes during late gestation reduces thermogenesis in newborn lambs by depressing fatty acid oxidation in perirenal brown adipose tissue. J Nutr 137(1):43-48.

Clarke L, Bryant M, Lomax M, Symonds M. 1997. Maternal manipulation of brown adipose tissue and liver development in the ovine fetus during late gestation. $\mathrm{J}$ Nutr 77(6):871-883.

Clarke L, Symonds M. 1998. Thermoregulation in newborn lambs: influence of feeding on ambient temperature on brown adipose tissue. Exp Physiol 83:651-657.

Corah L, Dunn T, Kaltenbach C. 1975. Influence of prepartum nutrition on the reproductive performance of beef females and the performance of their progeny. J Anim Sci 41:819-824. 
D'Souza A, Parikh N, Kaech S, Shadel G. 2007. Convergence of multiple signaling pathways is required to coordinately up-regulate mtDNA and mitochondrial biogenesis during T cell activation. Mitochondrion 7(6):374-385.

Dietz RE, Hall JB, Whittier WD, Elvinger F, Eversole DE. 2003. Effects of feeding supplemental fat to beef cows on cold tolerance in newborn calves. J Anim Sci 81(4):885-894.

Dunlap K, Filant J, Hayashi K, Rucker E, Song G, Deng J, Behringer R, Demayo F, Lydon J, Jeong J, Spencer TE. 2011. Postnatal deletion of Wnt7a inhibits uterine gland morphogenesis and compromises adult fertility in mice. Biol Reprod:In press.

Enerbäck S. 2009. The origins of brown adipose tissue. N Engl J Med 360(19):20212023.

Flynn NE, Meininger CJ, Haynes TE, Wu G. 2002. The metabolic basis of arginine nutrition and pharmacotherapy. Biomed Pharmacother 56(9):427-438.

Ford S, Zhang L, Zhu M, Miller M, Smith D, Hess B, Moss G, Nathanielsz P, Nijland M. 2009. Maternal obesity accelerates fetal pancreatic beta-cell but not alpha-cell development in sheep: prenatal consequences. Am J Physiol Regul Integr Comp Physiol 297(3):R835-843.

Frühbeck G, Becerril S, Sáinz N, Garrastachu P, García-Velloso MJ. 2009. BAT: a new target for human obesity? Trends Pharmacol Sci 30(8):387-396.

Fu W, Haynes T, Kohli R, Hu J, Shi W, Spencer TE, Carrol R, Meininger C, Wu G. 2005. Dietary L-arginine supplementation reduces fat mass in Zucker diabetic fatty rats. J Nutr 135(4):714-721.

Glick Z, Wickler S, Stern J, Horwitz B. 1984. Blood flow into brown fat of rats is greater after a high carbohydrate than after a high fat test meal. J Nutr 114(10):1934-1939.

Gonzalez-Barroso MDM, Ricquier D, Cassard-Doulcier AM. 2000. The human uncoupling protein-1 gene (UCP1): present status and perspectives in obesity research. Obes Rev 1(2):61-72.

Gray A, Bartol FF, Taylor KM, Wiley AA, Ramsey WS, Ott TL, Bazer FW, Spencer TE. 2000. Ovine uterine gland knock-out model: effects of gland ablation on the estrous cycle. Biol Reprod 62(2):448-456. 
Guerra C, Koza RA, Yamashita H, Walsh K, Kozak LP. 1998. Emergence of brown adipocytes in white fat in mice is under genetic control. Effects on body weight and adiposity. J Clin Invest 102(2):412-420.

Hay N, Sonenberg N. 2004. Upstream and downstream of mTOR. Genes Dev 18:19261945.

Ishida M, Hiramatsu Y, Masuyama H, Mizutani Y, Kudo T. 2002. Inhibition of placental ornithine decarboxylase by DL-alpha-difluor-methyl ornithine causes fetal growth restriction in rat. Life Sci 70(12):1395-1405.

Jobgen W, Meininger C, Jobgen S, Li P, Lee M-J, Smith S, Spencer T, Fried S, Wu G. 2009. Dietary L-arginine supplementation reduces white fat gain and enhances skeletal muscle and brown fat masses in diet-induced obese rats. J Nutr 139(2):230-237.

Jobgen WS, Fried SK, Fu WJ, Meininger CJ, Wu G. 2006. Regulatory role for the arginine-nitric oxide pathway in metabolism of energy substrates. J Nutr Biochem 17(9):571-588.

Kikuchi-Utsumi K, Gao B, Ohinata H, Hashimoto M, Yamamoto N, Kuroshima A. 2001. Enhanced gene expression of endothelial nitric oxide synthase in brown adipose tissue during cold exposure. Am J Physiol Regul Integr Comp Physiol 282(2):R623-R626.

Kim J-Y, Burghardt R, Wu G, Johnson G, Spencer T, Bazer F. 2011. Select nutrients in the ovine uterine lumen. VIII. Arginine stimulates proliferation of ovine trophectoderm cells through MTOR-RPS6K-RPS6 signaling cascade and synthesis of nitric oxide and polyamines. Biol Reprod 84(1):70-78.

Klingenberg M, Echtay KS. 2001. Uncoupling proteins: the issues from a biochemist point of view. Biochem Biophys Acta 1504(1):128-143.

Konkar A, Zhai Y, Granneman G. 2000. b1-Adrenergic Receptors mediate b3adrenergic-independent effects of CGP 12177 in brown adipose tissue. Mol Pharmacol 52:252-258.

Koppen A, Kalkhoven E. 2010. Brown vs white adipocytes: The PPAR[gamma] coregulator story. FEBS Lett 584(15):3250-3259.

Kozak L, Anunciado-Koza R. 2008. UCP1: its involvement and utility in obesity. Int J Obes 32(7):S32-S38. 
Krauss S, Zhang CY, Lowell BB. 2005. The mitochondrial uncoupling-protein homologues. Nat Rev Mol Cell Biol 6:248 - 261.

Lammoglia MA, Bellows RA, Grings EE, Bergman JW. 1999a. Effects of prepartum supplementary fat and muscle hypertrophy genotype on cold tolerance in newborn calves. J Anim Sci 77(8):2227-2233.

Lammoglia MA, Bellows RA, Grings EE, Bergman JW, Short RE, MacNeil MD. 1999b. Effects of feeding beef females supplemental fat during gestation on cold tolerance in newborn calves. J Anim Sci 77(4):824-834.

Lassala A, Bazer F, Cudd T, Datta S, Keisler D, Satterfield MC, Spencer T, Wu G. 2011. Parenteral administration of L-arginine enhances fetal survival and growth in sheep carrying multiple fetuses. J Nutr 141(5):849-855.

Lehr L, Canola K, Asensio C, Jimenez M, Kuehne F, Giacobino J-P, Muzzin P. 2006. The control of UCP1 is dissociated from that of PGC-1[alpha] or of mitochondriogenesis as revealed by a study using [beta]-less mouse brown adipocytes in culture. FEBS Lett 580(19):4661-4666.

Lin J, Wu P-H, Tarr PT, Lindenberg KS, St-Pierre J, Zhang C-y, Mootha VK, Jäger S, Vianna CR, Reznick RM, Cui L, Manieri M, Donovan MX, Wu Z, Cooper MP, Fan MC, Rohas LM, Zavacki AM, Cinti S, Shulman GI, Lowell BB, Krainc D, Spiegelman BM. 2004. Defects in adaptive energy metabolism with CNS-linked hyperactivity in PGC-1 \pm null mice. Cell 119(1):121-135.

Lindgren G, Barnard T. 1972. Changes in interscapular brown adipose tissue of rat during perinatal and early postnatal development and after cold acclimation : IV. Morphometric investigation of mitochondrial membrane alterations. Exp Cell Res 70(1):81-90.

Long NM, George LA, Uthlaut AB, Smith DT, Nijland MJ, Nathanielsz PW, Ford SP. 2010. Maternal obesity and increased nutrient intake before and during gestation in the ewe results in altered growth, adiposity, and glucose tolerance in adult offspring. J Anim Sci 88(11):3546-3553.

Matthias A, Ohlson KB, Fredriksson JM, Jacobsson A, Nedergaard J, Cannon B. 2000. Thermogenic responses in brown fat cells are fully UCP1-dependent. UCP2 or UCP3 do not substitute for UCP1 in adrenergically or fatty acid-induced thermogenesis. J Biol Chem 275(33):25073-25081.

Morrison S. 2004. Central pathways controlling brown adipose tissue thermogenesis. News Physiol Sci 19(2):67-74. 
Mostyn A, Wilson V, Dandrea J, Yakubu DP, Budge H, Alves Guerra MC, Pecqueur C, Miroux B, Symonds ME, Stephenson T. 2003. Ontogeny and nutritional manipulation of mitochondrial protein abundance in adipose tissue and the lungs of postnatal sheep. Br J Nutr 90(2):323-328.

Mozo J, Emre Y, Bouillaud F, Ricquier D, Criscuolo F. 2005. Thermoregulation: what role for UCPs in mammals and birds? Biosci Rep 25(3):227-249.

Nagashima T, Ohinata H, Kuroshima A. 1994. Involvement of nitric oxide in noradrenaline-induced increase in blood flow through brown adipose tissue. Life Sci 54(1):17-25.

Nedergaard J, Becker W, Cannon B. 1983. Effects of dietary essential fatty acids on active thermogenin content in rat brown adipose tissue. J Nutr 113:1717-1724.

Nedergaard J, Matthias A, Golozoubova V, Jacobsson A, Cannon B. 1999. UCP1: the original uncoupling protein--and perhaps the only one? New perspectives on UCP1, UCP2, and UCP3 in the light of the bioenergetics of the UCP1-ablated mice. J Bioenerg Biomembr 31(5):475-491.

Nicholls D, Cunningham S, Rial E. 1986. The bioenergetic mechanisms of brown adipose tissue thermogenesis. In: Trayhurn P, Nicholls D, editors. Brown Adipose Tissue. London. pp 52-85.

Nicholls DG, Lindberg O. 1973. Brown-sdipose-tissue mitochondria. Eur J Biochem $37(3): 523-530$.

Nisoli E, Clementi E, Moncada S, Carruba M. 2004. Mitochondrial biogenesis as a cellular signaling framework. Biochem Pharmocol 67(1):1-15.

Nisoli E, Clementi E, Paolucci C, Cozzi V, Tonello C, Sciorati C, Bracale R, Valerio A, Francolini M, Moncada S, Carruba M. 2003. Mitochondrial biogenesis in mammals: the role of endogenous nitric oxide. Science 299(5608):896-899.

Nisoli E, Clementi E, Tonello C, Sciorati C, Briscini L, Carruba M. 1998. Effects of nitric oxide on proliferation and differentiation of rat brown adipocytes in primary cultures. Br J Pharmacol 125:888-894.

Nisoli E, Tonello C, Briscini L, Carruba M. 1997. Inducible nitric oxide synthase in rat brown adipocytes: implications for blood flow to brown adipose tissue. Endocrinology 138:676-682. 
Nowak R, Porter RH, Lvy F, Orgeur P, Schaal B. 2000. Role of mother-young interactions in the survival of offspring in domestic mammals. Rev Reprod $5(3): 153-163$.

Petrovic V, Korac A, Buzadzic B, Korac B. 2005. The effects of L-arginine and LNAME supplementation on redox-regulation and thermogenesis in interscapular brown adipose tissue. J Exp Biol 208:4263-4271.

Power G. 1989. Biology of temperature: the mammalian fetus. J Dev Physiol 12(6):295304.

Puigserver P, Wu Z, Park CW, Graves R, Wright M, Spiegelman BM. 1998. A coldinducible coactivator of nuclear receptors linked to adaptive thermogenesis. Cell 92(6):829-839.

Rial E, Zardoya R. 2009. Oxidative stress, thermogenesis and evolution of uncoupling proteins. J Biol 8(6):58.

Richard D, Picard F. 2011. Brown fat biology and thermogenesis. Front Biosci 16:12331260 .

Satterfield M, Wu G. 2011. Brown adipose tissue growth and development: significance and nutritional regulation. Front Biosci 16:1589-1608.

Satterfield MC, Bazer FW, Smith SB, Spencer TE, Wu G. 2009. Arginine nutrition and fetal brown fat development. Amino Acids 37(Suppl. 1):6-7.

Seale P, Bjork B, Yang W, Kajimura S, Chin S, Kuang S, Scime A, Devarakonda A, Conroe H, Erdjument-Bromage H, Tempst P, Rudnicki M, Beier D, Spiegelman B. 2008. PRDM16 controls a brown fat/skeletal muscle switch. Nature 454:961 967.

Shi W, Meininger C, Haynes T, Hatakeyama K, Wu G. 2004. Regulation of tetrahydrobiopterin synthesis and bioavailability in endothelial cells. Cell Biochem Biophys 41(3):415-433.

Shiell AW, Campbell DM, Hall MH, Barker DJ. 2000. Diet in late pregnancy and glucose-insulin metabolism of the offspring 40 years later. BJOG 107(7):890895.

Simpson L. 1995. Sheep and Lambs Death Loss. Washington D.C.: United States Department of Agriculture. 
Smith SB, Prior R. 1984. Metabolic responses to fasting and alloxan-induced diabetes mellitus in steers. Am J Vet Res 45(9):1829-1834.

Srinivasan M, Katewa S, Palaniyappan A, Pandya J, Patel M. 2006. Maternal high-fat diet consumption results in fetal malprogramming predisposing to the onset of metabolic syndrome-like phenotype in adulthood. Am J Physiol Endocrinol Metab 291(4):E792-799.

Symonds M, Lomax MA. 1992. Maternal and environmental influences on thermoregulation in the neonate. Proc Nutr Soc 51:165-172.

Thomson D, Fick G, Gordon S. 2008. AMPK activation attenuates S6K1, 4E-BP1, and eEF2 signaling responses to high-frequency electrically stimulated skeletal muscle contractions. J Appl Physiol 104(3):625-632.

Timmons J, Wennmalm K, Larsson O, Walden T, Lassmann T, Petrovic N, Hamilton D, Gimeno R, Wahlestedt C, Baar K, Nedergaard J, Cannon B. 2007. Myogenic gene expression signature establishes that brown and white adipocytes originate from distinct cell lineages. Proc Natl Acad Scie U S A 104(11):4401-4406.

Ukropec J, Anunciado R, Ravussin Y, Hulver M, Kozak L. 2006. UCP1-independent thermogenesis in white adipose tissue of cold-acclimated Ucp1-/- mice. J Biol Chem 281(42):31894-31908.

Uldry M, Yang W, St Pierre J, Lin J, Seale P, Spiegelman B. 2006. Complementary action of the PGC-1 coactivators in mitochondrial biogenesis and brown fat differentiation. Cell Metab 3(5):333-341.

Virtanen K, Lidell M, Orava J, Heglind M, Westergren R, Niemi T, Taittonen M, Laine J, Savisto N, Enerbäck S, Nuutila P. 2009. Functional brown adipose tissue in healthy adults. N Engl J Med 360:1518-1525.

Voet D, Voet J, Pratt C. 2008. Fundamentals of Biochemistry. New Jersey: John Wiley \& Sons, Inc.

Vosatka R, Hassoun P, Harvey-Wilkes K. 1998. Dietary L-arginine prevents fetal growth restriction in rats. Am J Obstet Gynecol 178(2):242-246.

Warrington B, Byers F, Schelling G, Forrest D, Baker J, Greene L. 1988. Gestation nutrition, tissue exchange and maintenance requirements of heifers. J Anim Sci 66:774-782.

Watson R. 1972. Observed levels of mortality in relation to lambing and early stages of growth of sheep in Australia. World Rev Anim Prod 8:104-113. 
Won Park K, Halperin DS, Tontonoz P. 2008. Before they were fat: adipocyte progenitors. Cell Metab 8(6):454-457.

Wu G, Bazer F, Davis T, Kim S, Li P, Marc Rhoads J, Carey Satterfield M, Smith S, Spencer T, Yin Y. 2009. Arginine metabolism and nutrition in growth, health and disease. Amino Acids 37(1):153-168.

Wu G, Bazer FW, Cudd T, Meininger CJ, Spencer TE. 2004. Maternal nutrition and fetal development. J Nutr 134(9):2169-2172.

Wu G, Bazer FW, Tou W. 1995. Developmental changes of free amino acid concentrations in fetal fluids of pigs. J Nutr 125(11):2859-2868.

Wu G, Collins J, Perkins Veazie P, Siddiq M, Dolan K, Kelly K, Heaps C, Meininger C. 2007. Dietary supplementation with watermelon pomace juice enhances arginine availability and ameliorates the metabolic syndrome in Zucker diabetic fatty rats. J Nutr 137(12):2680-2685.

Wu G, Morris SM. 1998. Arginine metabolism: nitric oxide and beyond. Biochem J 336(1):1-17.

Wu Z, Puigserver P, Andersson U, Zhang C, Adelmant G, Mootha V, Troy A, Cinti S, Lowell B, Scarpulla RC, Spiegelman BM. 1999. Mechanisms controlling mitochondrial biogenesis and respiration through the thermogenic coactivator PGC-1. Cell 98(1):115-124.

Yan X, Huang Y, Zhao J, Long N, Uthlaut A, Zhu M, Ford S, Nathanielsz P, Du M. 2011. Maternal obesity-impaired insulin signaling in sheep and induced lipid accumulation and fibrosis in skeletal muscle of offspring. Biol Reprod:In press.

Yao K, Yin Y, Chu W, Liu Z, Deng D, Li T, Huang R, Zhang J, Tan B, Wang W, Wu G. 2008. Dietary arginine supplementation increases mTOR signaling activity in skeletal muscle of neonatal pigs. J Nutr 138:867-872.

Zhang L, Long NM, Hein SM, Ma Y, Nathanielsz PW, Ford SP. 2011. Maternal obesity in ewes results in reduced fetal pancreatic $\hat{\mathrm{I}}^{2}$-cell numbers in late gestation and decreased circulating insulin concentration at term. Domest Anim Endocrinol 40(1):30-39. 


\section{VITA}

\section{Sorin Meredith Greff}

PO Box 644, Bandera, TX 78003

Niros87@neo.tamu.edu

\section{Education}

December 2009 B.S. in Animal Science, Texas A\&M University, College Station, TX

August 2011 M.S. in Physiology of Reproduction, Texas A\&M University, College Station, TX

Work Experience

January 2010-May 2011 Graduate Teaching Assistant, Dept. of Animal Science, Texas A\&M University

January 2010- August 2011 Graduate Research Assistant, Texas A\&M University

\section{Honors/Awards}

Invited member of Gamma Sigma Delta, Texas A\&M University Chapter. April 2011.

Oral presentation at Scientific Meeting

Greff SM, Wu G, Satterfield MC (2011) A novel role for arginine in enhancing neonatal thermogenesis. Southern Association of Agricultural Scientists February 6-8, 2011(Corpus Christi, TX) 